\title{
Targeting Immune Cells in the Tumor Microenvironment of HCC: New Opportunities and Challenges
}

\author{
Xiaopei Hao ${ }^{1 \dagger}$, Guangshun Sun ${ }^{2 \dagger}$, Yao Zhang ${ }^{1 \dagger}$, Xiangyi Kong ${ }^{1}$, Dawei Rong ${ }^{1}$, Jinhua Song ${ }^{1 *}$, \\ Weiwei Tang ${ }^{1 *}$ and Xuehao Wang ${ }^{1 *}$ \\ ${ }^{1}$ Hepatobiliary Center, The First Affiliated Hospital of Nanjing Medical University, Key Laboratory of Liver Transplantation, Chinese \\ Academy of Medical Sciences, NHC Key Laboratory of Living Donor Liver Transplantation, Nanjing Medical University, Nanjing, \\ China, ${ }^{2}$ Department of General Surgery, Nanjing First Hospital, Nanjing Medical University, Nanjing, China
}

\section{OPEN ACCESS}

Edited by:

Dechun Feng,

National Institute on Alcohol Abuse and Alcoholism (NIAAA), United States

Reviewed by:

Talib Hassan Ali,

University of ThiQar, Iraq

Saisha Nalawade,

Baylor College of Medicine,

United States

*Correspondence:

Xuehao Wang

wangxh@njmu.edu.cn

Weiwei Tang

1243773473twww@sina.com Jinhua Song

jinhuasongnanj@163.com

${ }^{\dagger}$ These authors share first authorship

Specialty section:

This article was submitted to

Molecular and Cellular Oncology,

a section of the journal

Frontiers in Cell and Developmental

Biology

Received: 14 September 2021

Accepted: 19 October 2021

Published: 12 November 2021

Citation:

Hao X, Sun G, Zhang $Y$, Kong $X$, Rong $D$, Song J, Tang $W$ and Wang $X$ (2021) Targeting Immune Cells in the

Tumor Microenvironment of HCC:

New Opportunities and Challenges.

Front. Cell Dev. Biol. 9:775462.

doi: 10.3389/fcell.2021.775462
Immune associated cells in the microenvironment have a significant impact on the development and progression of hepatocellular carcinoma (HCC) and have received more and more attention. Different types of immune-associated cells play different roles, including promoting/inhibiting $\mathrm{HCC}$ and several different types that are controversial. It is well known that immune escape of HCC has become a difficult problem in tumor therapy. Therefore, in recent years, a large number of studies have focused on the immune microenvironment of HCC, explored many mechanisms worth identifying tumor immunosuppression, and developed a variety of immunotherapy methods as targets, laying the foundation for the final victory in the fight against HCC. This paper reviews recent studies on the immune microenvironment of HCC that are more reliable and important, and provides a more comprehensive view of the investigation of the immune microenvironment of HCC and the development of more immunotherapeutic approaches based on the relevant summaries of different immune cells.

Keywords: HCC, TAM, NK cell, cancer immunotherapy, challenge, development

\section{INTRODUCTION}

Hepatocellular carcinoma (HCC) is the most common type of liver cancer, accounting for the sixth most common type of cancer and the second leading cause of death among all cancers (Ferlay et al., 2015). Due to changes in environmental factors, immunization and people's lifestyle, the incidence of HCC and HCC-related mortality are increasing all over the world. The latest research indicates that HCC accounts for approximately $85 \%$ of patients diagnosed with liver cirrhosis. Its 5 -year survival rate is only $18 \%$, second only to pancreatic cancer (Asafo-Agyei and Samant, 2021). With the improvement of the treatment level for HCC, a variety of treatment options such as liver transplantation, surgical removal, systemic therapy and liver targeted therapy are constantly enhanced and created. At present, only surgical treatment is considered as a potential radical treatment for HCC. But only 15\% of HCC patients have the opportunity to have surgery, most patients are found in the advanced stage (Roxburgh and Evans, 2008). Sorafenib is the only systemic medication approved by the FDA for advanced HCC. However, because of the overexpression of dihydropyrimine dehydrogenase, the multi-drug resistance gene MDR-1and p-glycoprotein gene products, HCC is regarded a chemotherapy-resistant tumour, and how to execute effective chemotherapy is still a major difficulty (Soini et al., 1996; Jiang et al., 1997; Kato et al., 2001). 


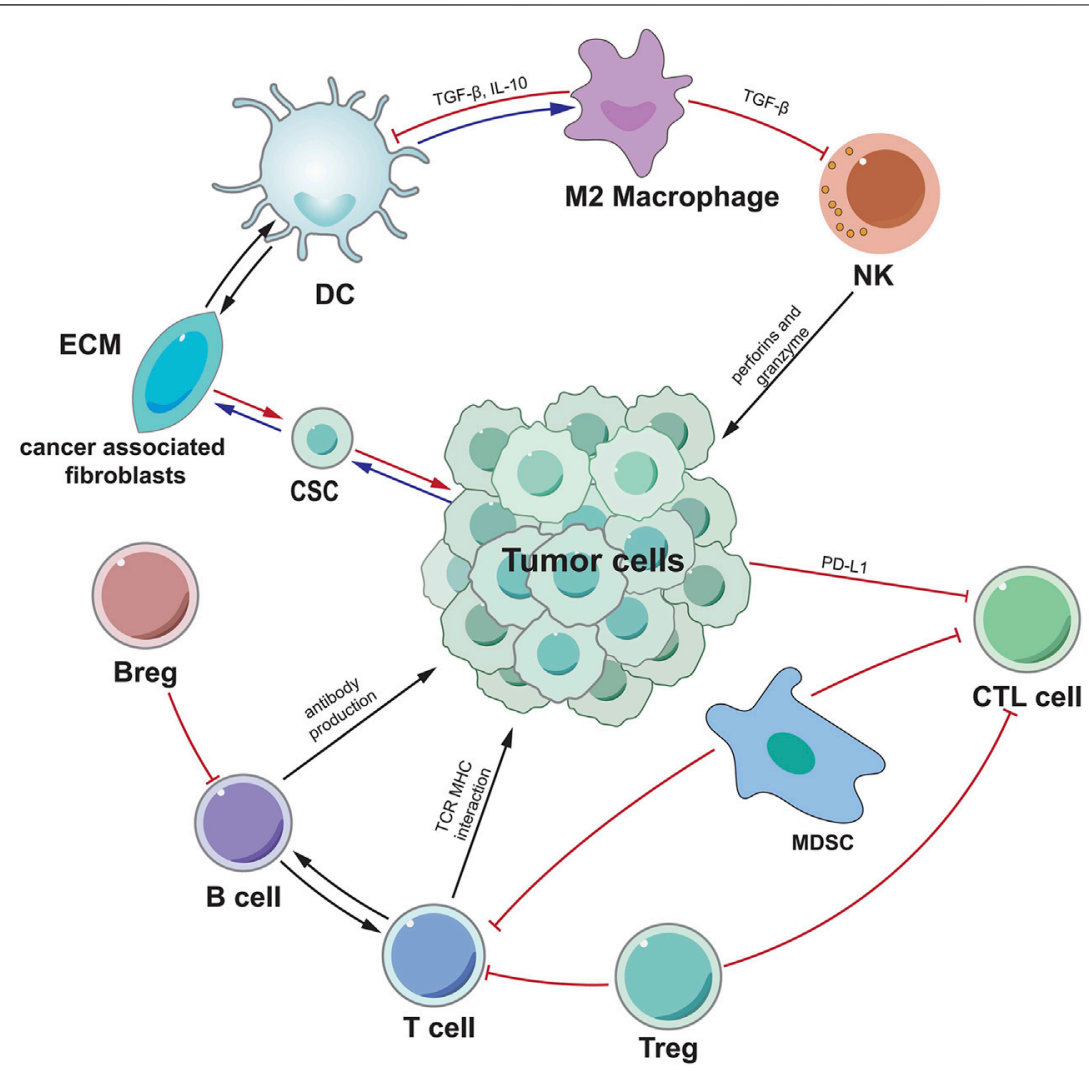

FIGURE 1 | A schematic overview of the most important mechanisms and interactions of the tumor microenvironment. Tumor cells interact with other cells in various ways. CSC indicates cancer stem cell, ECM indicates extracellular matrix, CTL indicates cytotoxic T lymphocytes.

Seven essential characteristics of cancer have been identified as crosstalk between cells and immune cells, self-sufficiency of signals for growth, unrestricted replication potential, apoptosis avoidance, growth signals insensitivity and continuous angiogenesis and invasion/metastasis of tissue (Hanahan and Weinberg, 2000; Hanahan and Weinberg, 2011). Tumor cells, immune cells, stromal cells, endothelial cells, and cancer-related fibroblasts are all found in the tumour microenvironment (TME), according to current research. Malignant tumour cells can evade immune monitoring and kill, as well as impair the human body, via a range of intricate ways (Hanahan and Weinberg, 2011). Due to the limitations of traditional chemotherapy regimens in the treatment of HCC, a variety of immunotherapy methods for HCC have been developed. Immunotherapy mostly employs immune cells within or outside of the TME to specifically target and assault cancer cells, with the benefits of high specificity and low side effects (Yost et al., 2019). More crucially, thanks to advances in tools such as mass spectrometry and single-cell RNA sequencing, We can map immunological cells in TMEs at the single-cell level (Spitzer and Nolan, 2016; Zheng et al., 2017; Papalexi and Satija, 2018; Wang et al., 2019a). We outline the significance of tumor-associated immune cells in the HCC tumour microenvironment and highlight their relevance in HCC cancer immunotherapy in this study.

\section{THE IMMUNE CELLS IN TME}

Tumor-associated immune cells are broadly classified into two types: tumor-promoting immune cells and tumor-antagonistic immune cells. At different stages of tumour formation, these two types of cells play different functions and impact each other (Figure 1). Because the significance of tumor-associated B cells in tumour growth is debatable, we shall introduce B cells additionally.

\section{TUMOR-ANTAGONIZING IMMUNE CELLS}

\section{Effector T Cells}

Current studies suggest that $\mathrm{CD} 8^{+}$cytotoxic $\mathrm{T}$ cells (CTLs) are the main lymphocytes that kill cancer cells. When $\mathrm{CD}^{+} \mathrm{T}$ cells recognize antibodies on $\mathrm{DC}, \mathrm{CD} 80^{-} \mathrm{CD} 86$ and $\mathrm{CD} 70$ ligands on $\mathrm{DC}$ connect to $\mathrm{CD} 27$ and $\mathrm{CD} 28$ receptors on $\mathrm{CD} 8^{+} \mathrm{T}$ cells, and $\mathrm{CD}^{+} \mathrm{T}$ cells are modified to become cytotoxic effector $\mathrm{CD} 8^{+}$ T cells (Tanaka et al., 1999; Farhood et al., 2019). Furthermore, $\mathrm{CD}^{+}{ }^{+} \mathrm{T}$ cells can activate $\mathrm{CD} 8^{+} \mathrm{T}$ cells through $\mathrm{CD} 40^{-} \mathrm{CD} 40 \mathrm{~L}$ interaction, and $\mathrm{CD} 4^{+} \mathrm{T}$ cells can produce $\mathrm{IL}-2$ to enhance $\mathrm{CD} 8^{+}$ $\mathrm{T}$ cell proliferation. $\mathrm{CD} 4^{+} \mathrm{T}$ cells are also important in the maturation of $\mathrm{CD}^{+} \mathrm{T}$ cells into memory cells (Bennett et al., 1997; Mackey et al., 1997; Bennett et al., 1998; Mackey et al., 1998; 
TABLE 1 | The immune cells in TME: Effector T cells.

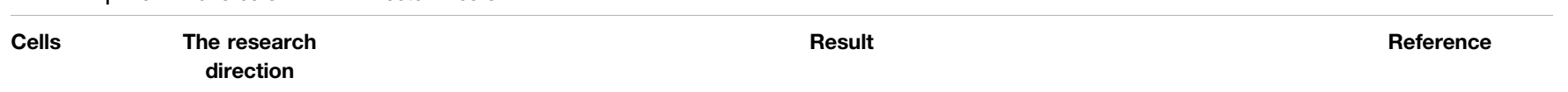

\section{$\mathrm{CD}^{+} \mathrm{T}$ cell The immune mechanism}

$\mathrm{CD}^{+} \mathrm{T}$ cell immunotherapy

$\mathrm{CD}^{+} \mathrm{T}$ cell Prognostic marker

$\mathrm{CD}^{+} \mathrm{T}$ cell immunotherapy

$\mathrm{CD}^{+} \mathrm{T}$ cell The immune mechanism

$\mathrm{CD}^{+} \mathrm{T}$ cell The immune mechanism

$\mathrm{CD}^{+} \mathrm{T}$ cell The immune mechanism

$\mathrm{CD}^{+} \mathrm{T}$ cell immunotherapy

$\mathrm{CD}^{+} \mathrm{T}$ cell The immune mechanism

$\mathrm{CD}^{+} \mathrm{T}$ cell The immune mechanism

$\mathrm{CD}^{+} \mathrm{T}$ cell immunotherapy

$\mathrm{CD}^{+} \mathrm{T}$ cell immunotherapy

$\mathrm{CD}^{+} \mathrm{T}$ cell The immune mechanism

$\mathrm{CD}^{+} \mathrm{T}$ cell Prognostic marker

$\mathrm{CD}^{+} \mathrm{T}$ cell immunotherapy

$\mathrm{CD}^{+} \mathrm{T}$ cell The immune mechanism

$\mathrm{CD}^{+} \mathrm{T}$ cell The immune mechanism

$\mathrm{CD}^{+} \mathrm{T}$ cell immunotherapy

$\mathrm{CD}^{+} \mathrm{T}$ cell Prognostic marker

$\mathrm{CD}^{+} \mathrm{T}$ cell immunotherapy

$\mathrm{CD}^{+} \mathrm{T}$ cell Prognostic marker

$\mathrm{CD}^{+} \mathrm{T}$ cell Prognostic marker

$\mathrm{CD}^{+} \mathrm{T}$ cell immunotherapy
NanoMnSor enhances the efficacy of anti-PD-1 antibodies and whole cell cancer vaccine

Chang et al. (2020) immunotherapy by reducing tumor invasion of hypoxia-induced tumor-associated macrophages, promoting macrophage polarization into an immune-stimulating M1 phenotype and increasing the number of CD8 cytotoxic $T$ to reprogram the immunosuppressive TME.

PVRL1 upregulated by HCC cells stabilizes PVR on the cell surface, which interacts with the inhibitory molecule TIGIT of CD8 effector memory T cells. It is possible to develop PVRL1/TIGIT inhibitors as well as anti-PD1 to treat HCC.

PD1 or TIM3PD1 CD8 T cells were significantly associated with poor prognosis, and the latter were adjacent to PD-L1 tumor-associated macrophages.

SFGL2 promotes HCC growth by reducing DC activity and subsequent cytotoxicity of CD8 T cells, suggesting that SFGL2 is a novel potential therapeutic target for HCC therapy.

IL-35 inhibits the cytolytic and noncytolytic functions of CD8 T cells against non-viral hepatitis associated HCC, possibly inhibiting the expression of perforin.

Suppression of the tumor immunosuppressive environment and immune escape is accompanied by proliferation of functional cytotoxic CD8 T cells as well as suppression of myeloid suppressor cells and regulatory $T$ cells in the tumor environment.

A large number of TEM-1 positive (TEM-1) TAM in the late stage of HCC development indirectly impair the cytotoxic function of CD8 T cells and induce the apoptosis of CD8 T cells.

The $\Delta$ - catenin peptide vaccine stimulates the activation of cytotoxic T lymphocytes (CTL) and enhances the invasion of $\mathrm{CD}^{+} \mathrm{T}$ cells into the tumor. In addition, $\Delta$ - catenin peptide vaccine can enhance the secretion of IFN- $\gamma$ and the killing effect of T cells on tumor cells.

Stat3-blocked lysates of whole HCC cells stimulated activation of T and natural killer (NK) cells and enhanced cytotoxic CD8 T cell infiltration in tumor tissues.

Antibody against CD274(PD-ligand 1 [PD-L1]), TIM3, or LAG3 increases CD8 and CD4 TIL proliferation and cytokine production in response to stimulation by polyclonal antigens or TAA.

Tremelimumab in combination with tumor ablation is a potential new therapy for patients with advanced $\mathrm{HCC}$, resulting in the accumulation of CD8 T cells in tumors. Positive clinical activity was observed and may replace HCV viral load.

PD-L1 upregulation is mainly induced by pre-existing activated CD8 ${ }^{+}$cytotoxic T cells in the HCC environment, rather than constitutively expressed by tumor cells, and is a favorable prognostic factor for HCC.

Expression of programmed death 1(PD-1) and programmed death ligand 1(PD-L1) correlated with $\mathrm{CD}^{+}$and $\mathrm{CD}^{+}$cell density and clinical outcome. High density of internal and peripheral $\mathrm{CD}^{+}$and $\mathrm{CD}^{+} \mathrm{T}$ cells and corresponding immune scores were significantly associated with lower recurrence rates and prolonged RFS.

Crosstalk of NK and CD8 T cells in tumor microenvironment may benefit patient prognosis. The count of NK and CD8 T cells infiltrating in CRC tumors may provide useful prognostic information

In the tumor microenvironment of sorafenib treated mice, tumor-specific effector $\mathrm{T}$ cells were upregulated, while the ratio of $\mathrm{CD} 8^{+} \mathrm{T}$ cells expressing $\mathrm{PD}-1$ and regulatory $\mathrm{T}$ cells (Tregs) was reduced. In HLA-A2 transgenic mice, the $\mathrm{CD}^{+} \mathrm{T}$ cells producing IFN- $\gamma$ and the cytolytic activity in vivo were significantly increased.

As the disease progresses from LC to HCC, the frequency of circulating PD-1 (+) CD8 ${ }^{+} \mathrm{T}$ cells increases. Tumor-infiltrating $\mathrm{CD}^{+} \mathrm{T}$ cells showed a dramatic increase in PD-1 expression. In vitro, CD8 ${ }^{+} \mathrm{T}$ cells induced PD-L1 expression on HCC cells in an IFN- $\gamma$ dependent manner, thereby promoting APOPTOSIS of CD8 ${ }^{+} \mathrm{T}$ cells, while blocking PD-L1 reversed this effect.

Strong TAA-specific $\mathrm{CD}^{+} \mathrm{T}$ cell response inhibited $\mathrm{HCC}$ recurrence. For patients with $\mathrm{HCC}$ following local therapy, induction of TAA-specific cytotoxic T lymphocytes should be considered with immunotherapy, such as peptide vaccine.

Overexpression of HLA-G protein in HCC is an independent indicator of poor prognosis, especially in early disease. The combination of HLA-G expression and Tregs/CD8+ ratio increased the prognostic power of both variables.

HCA661 peptides $\mathrm{H} 110$ and $\mathrm{H} 246$ are naturally processed in dendritic cells (DCs) and when applied to DCs, they are sufficient to induce autologous $C D 8^{+} \mathrm{T}$ cells to initiate cytotoxic responses against HCA661(+) human cancer cells.

The combination of low intratumoral Tregs with high intratumoral activated CD8 ${ }^{+}$cytotoxic cells (CTL) is the balance of CTL and is an independent prognostic factor for improved DFS and OS.

Increased CD4 (+) CD25 (+) Foxp3 (+) Treg may impair effector function of CD8 ${ }^{+} \mathrm{T}$ cells, promote disease progression, and represent a potential prognostic marker and therapeutic target in HBVassociated HCC patients.

The functionally detectable presence of M3 (271) specific CD8 ${ }^{+}$T cells in HCC patients makes M3 (271) a potential target for immunotherapy in these patients. CD8 ${ }^{+} \mathrm{T}$ cells that respond to both NY-ESO-1 and MAG-A3 antigens provide a theoretical basis for the use of a bivalent vaccine in HCC patients with tumors expressing both antigens.
Chiu et al. (2020)

Ma et al. (2019)

Yang et al. (2019a)

Yang et al. (2019b)

Tao et al. (2019)

Wu et al. (2019a)

Huang et al. (2018)

Han et al. (2017)

Zhou et al. (2017)

Duffy et al. (2017)

Xie et al. (2016)

Gabrielson et al. (2016)

Sconocchia et al. (2014)

Chen et al. (2014)

Chen et al. (2012)

Shi et al. (2011)

Hiroishi et al. (2010)

Cai et al. (2009)

Pang et al. (2007)

Gao et al. (2007)

Fu et al. (2007)

Zhang et al. (2007)

(Continued on following page) 
TABLE 1 | (Continued) The immune cells in TME: Effector T cells.

\begin{tabular}{|c|c|c|c|}
\hline Cells & $\begin{array}{c}\text { The research } \\
\text { direction }\end{array}$ & Result & Reference \\
\hline
\end{tabular}

$\mathrm{CD}^{+} \mathrm{T}$ cell Prognostic marker

$\mathrm{CD}^{+} \mathrm{T}$ cell The immune mechanism

CD4+T cell The immune mechanism

CD4+T cell The immune mechanism

CD4+T cell The immune mechanism

CD4+T cell The immune mechanism

CD4+T cell The immune mechanism

CD4+T cell The immune mechanism

CD4+T cell The immune mechanism

$\mathrm{CD} 4+\mathrm{T}$ cell immunotherapy

CD4+T cell immunotherapy

CD4+T cell The immune mechanism

CD4+T cell The immune mechanism

CD4+T cell The immune mechanism

CD4+T cell immunotherapy CD4+T cell The immune
mechanism

CD4+T cell immunotherapy

CD4+T cell Prognostic marker

CD4+T cell The immune mechanism

CD4+T cell The immune mechanism

CD4+T cell Prognostic marker

CD4+T cell immunotherapy

CD4+T cell The immune mechanism CD4+T cell immunotherapy
HCC patients showed significantly higher WT p53-specific memory CD8 ${ }^{+} \mathrm{T}$ cell frequency and stronger WT p53-specific CTL activity compared to healthy controls. Increased frequency and activity of P53 specific CD8 ${ }^{+} T$ cells were associated with deletion of selective HLA-A2 alleles and decreased expression of co-stimulatory molecules in tumor cells.

$\mathrm{CD} 4^{+} \mathrm{CD} 25^{+} \mathrm{T}$ cells in the peripheral region of $\mathrm{HCC}$ may play a key role in controlling the activity of $\mathrm{CD} 8^{+}$ cytotoxic $\mathrm{T}$ cells, thus promoting the development of HCC.

The C/eBPa/miR-7 axis negatively regulates CD4+T cell activation and function through MAPK4, thus orchestrating experimental $\mathrm{AlH}$ mice.

In vivo treatment with MYC ASO without control ASO reduced proliferation, induced apoptosis, increased senescence, and remodeled the tumor microenvironment by recruiting CD4+T cells

Tumor associated CD4/CD8 double positive T (DPT) cells were found to be rich in $L$ region, with coexpression of PD-1/HLA-DR/ICOS/CD45RO, and showed high levels of IFN-, TNF- and -1 after PD stimulation. Enrichment of DPT and PD-1DPT in $L$ region indicated a good prognosis.

The recruitment of cytotoxic cells, namely terminally differentiated $\mathrm{CD} 4^{+}$and $\mathrm{CD} 8^{+} \mathrm{T}$ cells (TEFF), is impaired in the tumor, and the effector memory $\mathrm{CD}^{+} \mathrm{T}$ cells are more attracted in this region.

Knockdown of DCR3 expression in HCC significantly restored the immunity of CD4+T cells. Inhibition of DCR3 expression may provide a novel immunotherapy approach to restore immunity in HCC patients Activated $\mathrm{CD} 4+\mathrm{T}$ cells from HCC stimulate macrophages to produce $\mathrm{C}-\mathrm{X}-\mathrm{C}$ motif chemokine 10(CXCL10). CXCL10 binds to the CXC chemokine receptor 3 on B cells and signals them through extracellular signal-regulated kinases, making them plasma cells that produce IgG.

In a study of mice with liver tumors, CXCR6 was found to mediate the removal of NKT cells and CD4+T cells from senescent liver cells.

Liver-specific MYC transgenic mice fed the MCD diet were induced. Blockage of CPT with the pharmacological inhibitor perhexiline reduced apoptosis of CD4+T cells in the liver and inhibited tumor formation in HCC. These results provide useful information for the potential targeting of the CPT family to salvage intrahepatic CD4+T cells and for immunotherapy to assist NAFLD-promoted HCC.

Tumor-infiltrating LY6G MDSCs from orthotopic liver tumors treated with sorafenib significantly induced CD4+T cells expressing IL-10 and TGF- $\beta$ and down-regulated the cytotoxic activity of CD8 T cells.

Antibody against CD274(PD-ligand 1 [PD-L1]), TIM3, or LAG3 increases CD8 and CD4 TIL proliferation and cytokine production in response to stimulation by polyclonal antigens or TAA.

Blockage of PD-L1 can restore IFN $\gamma / T N F-\alpha$ production in BTLAPD-1 tumor CD4+T cells, but partially inhibit the activation of BTLAPD-1 CD4+T cells.

CB2 inactivation reduces expression of T cell recruitment chemokines and inhibits liver T cell recruitment, including specific $\mathrm{CD}^{+} \mathrm{T}$ cells.

IFN $\gamma$ enzym-linked immunodot assay demonstrated that they induced antigenicity of specific

$\mathrm{CD} 4+\mathrm{T}$ cells in healthy donors or in HCC patients before and after GPC3-SP vaccine administration. The natural processing of these epitopes was demonstrated by the immune response of helper $T$ cells to dendritic cells (DCs) loaded with GPC3.

TGF- $\beta$ expression was upregulated in DEN induced HCC mouse model. TGF- $\beta$ promotes the differentiation of Foxp3 (+) CD4 (+) T cells (Treg cells) in vitro.

Intra-tumor combined administration of SLC and anti-CD25 mAb significantly reduced the frequency of Treg and increased the number of $\mathrm{CD} 8^{+}$and $C D 4^{+} T$ cells in tumor sites, and also maximally inhibited the growth and invasion of HCC.

The high expression of IL-17 and IL-17RE is a promising predictor of poor prognosis in HCC. The precursor capacity of the $\mathrm{CD} 4^{+} \mathrm{T}$ cells that produce $\mathrm{LL}-17$ may be involved in cross-talk of different types of inflammatory/immune cells than in HCC.

CD25-Foxp3-T cells with a CD127-IL-10 + phenotype can be induced in vitro from naive CD4 (+) T cells involving programmed cell death 1 ligand 1, immunoglobulin-like transcript4, and human leukocyte antigen G.

In vitro restimulation experiments and in vivo depletion studies have shown that both $\mathrm{CD} 4^{+}$and $\mathrm{CD} 8^{+}$ cells contribute to antitumor activity. Using PBMC from healthy volunteers and patients with $\mathrm{HCC}$, it was shown that ASPH stimulation led to significant development of antigen-specific $C D 4^{+} \mathrm{T}$ cells.

Lack of recovered CD19, CD3, CD8, and especially CD4+T cells is associated with poor survival in patients.

Tregs significantly increased the inhibition of $\mathrm{CD}^{+}$and CD4 (+) T cell proliferation and cytokine secretion, and increased numbers of circulating CD4 (+) CD25 (+) Foxp3 (+) Tregs and tumor-infiltrating Foxp3 (+) cells prior to cryoablation were associated with a higher risk of recurrence or progression in HCC patients after cryoablation.

MDSC exerts its immunosuppressive function by inducing CD4 (+) CD25 (+) Foxp3 (+) regulatory T cells in co-cultured CD4 (+) T cells.

$\mathrm{CD}^{+} \mathrm{T}$ cells killed gene-independent CT26 cells and even homologous HEPA1- 6 cells. In mice treated with $\mathrm{DC} / \mathrm{BNL}+\mathrm{IL}-12$, a large number of $\mathrm{CD} 4^{+} \mathrm{T}$ cells and $\mathrm{MHC}$ class $\|$ positive macrophages infiltrated the tumor tissue.
Cicinnati et al. (2006)

Yang et al. (2006)

Zhao et al. (2020)

Dhanasekaran et al.

(2020)

Zheng et al. (2020a)

Chaoul et al. (2020)

Zhu et al. (2019)

Wei et al. (2019)

Mossanen et al. (2019)

Brown et al. (2018)

Chang et al. (2018)

Zhou et al. (2017)

Zhao et al. (2016)

Suk et al. (2016)

Sayem et al. (2016)

Shen et al. (2015)

Chen et al. (2013)

Liao et al. (2013)

Kakita et al. (2012)

Shimoda et al. (2012)

Carr and Metes, (2012)

Zhou et al. (2010)

Hoechst et al. (2008)

Homma et al. (2005)

(Continued on following page) 
TABLE 1 | (Continued) The immune cells in TME: Effector T cells.

\begin{tabular}{|c|c|c|c|}
\hline Cells & $\begin{array}{l}\text { The research } \\
\text { direction }\end{array}$ & Result & Reference \\
\hline CD4+T cell & $\begin{array}{l}\text { The immune } \\
\text { mechanism }\end{array}$ & $\begin{array}{l}\text { TRAIL receptors on HCC cells were upregulated by 5-FU, and TRAIL on CD4 (+) T cells, CD14 (+) } \\
\text { monocytes and CD56 (+) NK cells was induced by IFNa. }\end{array}$ & Yamamoto et al. (2004) \\
\hline CD4+T cell & $\begin{array}{l}\text { The immune } \\
\text { mechanism }\end{array}$ & $\begin{array}{l}\text { IFN- } \gamma \text { was produced by incubation with } \mathrm{DC} / \mathrm{MIH}-2 \text { from } \mathrm{CD} 4(+) \mathrm{T} \text { cells but not from } \mathrm{CD}^{+} \mathrm{T} \text { cells of } \\
\text { inoculated mice. Anti-IFN- } \gamma \text { antibody attenuated the cytotoxicity of spleen cells. Immunization of CD4 (+) } \\
\text { T cells with DCs loaded with homologous } \mathrm{HCC} \text { cells, which produce IFN- } \gamma \text { in response to HCC antigens, } \\
\text { leads to activation of macrophages that kill liver tumor cells at an early stage. }\end{array}$ & Irie et al. (2004) \\
\hline
\end{tabular}

Schoenberger et al., 1998; Bourgeois et al., 2002; Cheng et al., 2002; Borst et al., 2018). CTL kills target cells through granular exocytosis and apoptotic induction mediated by FasL ligand (FasL) in working state. CTL can also produce interferon(IFN-) and tumour necrosis factor (TNF-) to cause cancer cell cytotoxicity (Farhood et al., 2019). Activation and regulation of CTL requires signals from $\mathrm{T}$ cell receptors (TCR) and immune checkpoints (Rogler et al., 1999). For example, cancer cells inhibit CTL activity through the expression of a ligand that binds to an inhibitory checkpoint, such as PD-L1 (Iwai et al., 2002). A significant number of studies have established the function of $\mathrm{CD}^{+} \mathrm{T}$ cells and $\mathrm{CD} 4^{+} \mathrm{T}$ cells in the formation and progression of HCC, including diagnosis/treatment/prognosis, and so on.

Chang et al. 's study confirmed that NanoMnSor improves the effectiveness of anti-PD-1 antibodies and whole-cell cancer vaccine immunotherapy by encouraging macrophage polarization to an immunostimulating M1 phenotype, decreasing hypoxica-induced tumor infiltration of tumorassociated macrophages, and raising the number of CD8 cytotoxic $\mathrm{T}$ cells in tumors, thereby reprogramming immunosuppressive TME (Chang et al., 2020). Xie et al. 's research proposed that PD-L1 overexpression is mostly triggered by pre-existing activated CD8 $(+)$ cytotoxic T cells in the HCC environment, rather than being produced constitutively by tumor cells, and that it is a good prognostic factor for HCC (Xie et al., 2016). The frequency of circulating PD-1 (+) CD8 (+) $\mathrm{T}$ cells increases as the illness develops from LC to HCC. PD-1 expression was shown to be much higher in tumor-infiltrating CD8 (+) $\mathrm{T}$ cells. In vitro, CD8 (+) $\mathrm{T}$ cells promoted the production of PD-L1 on HCC cells in an IFN-dependent way, increasing CD8 (+) T cell death, whereas inhibiting PD-L1 reversed this effect (Shi et al., 2011).

Both in vitro restimulation and in vivo depletion studies have indicated that $\mathrm{CD} 4^{+}$and $\mathrm{CD}^{+}$lymphocytes contribute to anticancer activity. ASPH activation resulted in considerable production of antigen-specific $\mathrm{CD}^{+}{ }^{+} \mathrm{T}$ cells in PBMC from healthy volunteers and HCC patients (Shimoda et al., 2012). Lack of recovered $\mathrm{CD} 19^{+}, \mathrm{CD}^{+}, \mathrm{CD}^{+}$, and especially CD ${ }^{+}$ $\mathrm{T}$ cells is associated with poor survival in patients (Carr and Metes, 2012). Zhou et al. 's revealed that antibodies against CD274 (PD-L1), LAG3, or TIM3 boost $\mathrm{CD}^{+}$and CD8 ${ }^{+}$TIL proliferation and cytokine secretion in response to polyclonal antigens or TAA stimulation (Zhou et al., 2017). More research results on the effect of Effector T cells in HCC are summarized in Table 1. It is clear that Effector $\mathrm{T}$ cells play a critical role in the immunological milieu of HCC. Many studies have shown that targeting these cells is effective in patients with HCC.

\section{NK Cells}

NK cells are an essential anti-tumor immune cell that primarily mediates immune surveillance of malignancies. It performs a similar function as $\mathrm{CD}^{+} \mathrm{T}$ cells: NK cells regulate the killing response of tumor cells by releasing perforin and granulein, triggering apoptosis in target cells. In addition, to improve their anticancer activity, NK cells can produce proinflammatory cytokines and chemokines (Voskoboinik et al., 2006; Guillerey et al., 2016; Habif et al., 2019). Existing studies have confirmed the value of NK cells in the development, targeted therapy, prognosis of HCC. Sprinzl et al. 's research confirmed that Sorafenib can promote the pro-inflammatory response of tumor-associated macrophages in HCC, and then activate the anti-tumor $\mathrm{NK}$ cell response through the cytokine and NF- $\kappa$ B pathway (Sprinzl et al., 2013). Senescence monitoring necessitates the recruitment and maturation of CCR2 myeloid cells, and CCR2 deficiency promotes HCC growth. Conversely, HCC cells suppress the maturation of recruited myeloid progenitors, which promotes mice HCC growth and worsens prognosis and survival in human HCC patients via NK cell inhibition (Eggert et al., 2016). Kohga et al. 's revealed that natural killer (NK) cells had stronger cytolytic activity on ADAM9KD-HCC cells than on control cells, and that this cytotoxicity is enhanced by the MICA/B and NK group 2, D pathways. Sorafenib treatment resulted in a decrease in ADAM9 expression in HCC cells, an increase in membrane-bound MICA expression, and a decrease in the quantity of soluble MICA. Sorafenib increased HCC cell NK sensitivity by boosting the expression of membrane-bound MICA (Kohga et al., 2010a). Table 2 summarizes current research on NK cells in HCC, confirming the importance of NK cells in immune escape and anti-HCC therapy.

\section{Dendritic cells}

DC cells, as specialized antigen-presenting cells in the human body, can present antigens to $\mathrm{T}$ cells and produce costimulatory signals for $\mathrm{T}$ cell activation. According to the current study, mature DC cells can penetrate tumor cells and limit tumor incidence and progression. Under many severe conditions, this inhibition effect will be avoided by tumors through certain means. Therefore, targeting at DC cells, some studies have reported its role in the occurrence, development, immunotherapy, diagnosis and prognosis of HCC. For 
TABLE 2 | The immune cells in TME: NK cells.

$\begin{array}{ccc}\text { Cells } & \text { The research } \\ \text { direction } & \text { Result }\end{array}$

\begin{tabular}{|c|c|c|}
\hline $\begin{array}{l}\text { NK } \\
\text { cells }\end{array}$ & immunotherapy & $\begin{array}{l}\text { Sorafenib can promote the pro-inflammatory response of tumor-associated macrophages in HCC, and } \\
\text { then activate the anti-tumor NK cell response through the cytokine and NF-kB pathway. }\end{array}$ \\
\hline $\begin{array}{l}\text { NK } \\
\text { cells }\end{array}$ & $\begin{array}{l}\text { The immune } \\
\text { mechanism }\end{array}$ & $\begin{array}{l}\text { NK cell activator Poly }(\mathrm{I}: \mathrm{C}) \text { promotes } \mathrm{HCC} \text { in HBs-Tg mice. Poly (I:C) induces liver inflammation and liver cell } \\
\text { damage in HBs-Tg mice. The increase of hepatocyte EMT depends on the presence of NK cells in HBs-Tg } \\
\text { mice. IFN- } \gamma \text { derived from NK cells plays a key role in the development of HCC in HBs-Tg mice. }\end{array}$ \\
\hline $\begin{array}{l}\text { NK } \\
\text { cells }\end{array}$ & $\begin{array}{l}\text { The immune } \\
\text { mechanism }\end{array}$ & $\begin{array}{l}\text { The phenotype of peripheral blood NK cells was biased towards the defect/fatigue immune pattern, and } \\
\text { the frequency of cells expressing NKp30 and member D of natural killer group } 2 \text { decreased, and the } \\
\text { proportion of cells expressing T cell immunoglobulin and mucin domain increased. In addition, nKP30- } \\
\text { positive NK cells have reduced expression of NCR3 immunostimulated splicing variants and increased } \\
\text { expression of inhibitory variants, leading to NKP30-mediated loss of function in patients with advanced } \\
\text { tumors. }\end{array}$ \\
\hline
\end{tabular}

$\begin{array}{ll}\begin{array}{l}\text { NK } \\ \text { cells } \\ \text { NK } \\ \text { cells }\end{array} & \begin{array}{l}\text { The immune } \\ \text { mechanism }\end{array} \\ \text { NK } & \text { immunotherapy } \\ \text { cells } & \\ \text { NK } & \text { The immune } \\ \text { cells } & \text { mechanism } \\ \text { NK } & \text { The immune } \\ \text { cells } & \text { mechanism } \\ \text { NK } & \text { The immune } \\ \text { cells } & \text { mechanism } \\ \text { NK } & \text { The immune } \\ \text { cells } & \text { mechanism }\end{array}$

Blocking the CD96 ${ }^{-} \mathrm{CD} 155$ interaction restores NK cell immunity to tumor by reversing NK cell depletion or TGF- $\beta 1$ reversing NK cell depletion, suggesting that CD96 may have a therapeutic role in HCC.

When co-cultured with sorafenib treated $\mathrm{M} \varphi$, cytotoxic NK cells were activated, resulting in tumor cell death. In addition, sorafenib was found to down-regulate the expression of major histocompatibility complex I in tumor cells, which may reduce tumor response to immune checkpoint therapy and promote NK cell response.

Serum cholesterol accumulates in NK cells and activates their effect on HCC cells, increases the anti-tumor

Sprinzl et al. (2013)

Chen et al. (2019)

Mantovani et al. (2019) function of natural killer cells, and reduces the growth of liver tumors in mice.

CD48 protein was strongly expressed in HCC tissues but not in tumor liver monocytes. This monocyte induced NK cell dysfunction was significantly attenuated by blocking CD48 receptor 2B4 on NK cells, but not by blocking NKG2D and NKp30.

The cytotoxicity of NK cells in patients with HCC is reduced. MDSCs inhibit NK cell cytotoxicity and IFN- $\gamma$ release. MDSCs inhibit NK cells depending on cell contact. MDSCs inhibit NK cells for a long time. MDSCs use NKp30 receptors to inhibit NK cell function.

Compared with donor and recipient PB, donor liver NK cells showed the strongest cytotoxicity to HCC HepG2 after IL-2 stimulation. This may explain why liver natural killer (NK) cells have higher cytotoxic activity against tumor cells than peripheral blood (PB) NK cells.

SMICA derived from advanced HCC is responsible for NKG2D expression and NK cell function. NK cells stimulate DC maturation induced by human hepatoma cells and enhance the excitatory stimulation ability of DC. When NK cells were pretreated with serum containing SMicas, DC maturation and activation were completely eliminated.

NK immunotherapy

Leptin can significantly inhibit human HCC. This effect is mediated by inducing the proliferation and activation of natural killer cells and directly inhibiting tumor growth. The decreased NK expression of inhibitory CIS and the overexpression of anti-proliferative STAT2 and SOCS1 proteins in HCC lines may emphasize the anticancer effect of leptin.

NK The immune

cells mechanism

Smoking is associated with a decrease in the frequency of natural killer (NK) cells in the peripheral blood, which is characterized by a reduction in NK function through systemic immunology. The combination of smoking and lowering the frequency of NK cells further increases the likelihood of viral load and ALT $\geq 80$ U/L.

NK The immune

cells mechanism

NKT and CD4+T cells promote the elimination of senescent liver cells to prevent the occurrence of HCC, and this process requires CXCR6. CXCR6 inhibits the occurrence of $\mathrm{HCC}$ by promoting natural killer T and CD4+T cell-dependent senescence control.

NK immunotherapy

Using CAR transduced T cells and NK cells that recognize the surface marker CD147 (also known as Basigin), various malignant HCC cell lines were effectively killed in vitro, as well as HCC tumors in transplanted and patient-derived mouse models of transplanted tumors.

cells $\quad$ The immune

cells mechanism

The liver gene delivery of high IL-15 makes CD8 ${ }^{+} T$ cells and NK cells proliferate in large quantities, resulting in the accumulation of CD8 ${ }^{+} \mathrm{T}$ cells in the body (over 40 days), especially in the liver. Hyper-IL-15 therapy has significant therapeutic effects on established liver metastases and even autologous HCC induced by DEN. These effects can be depleted by $\mathrm{CD}^{+} \mathrm{T}$ cells instead of NK cells.

NK immunotherapy

The cytolytic activity of natural killer (NK) cells on ADAM9KD-HCC cells is higher than that on control cells, and the enhancement of this cytotoxicity depends on the MICA/B and NK group 2, D pathways. Sorafenib treatment resulted in a decrease in the expression of ADAM9 in HCC cells, an increase in the expression of membrane-bound MICA and a decrease in the level of soluble MICA. The addition of sorafenib enhanced the NK sensitivity of HCC cells by increasing the expression of membrane-bound MICA.

NK The immune ADAM9 protease plays a key role in the shedding of $\mathrm{MHC}$ class I related chain $\mathrm{A}$ (MICA) that regulates the sensitivity of tumor cells to natural killer cells (NK). The expression of ADAM9 in CD133si-PLC/PRF/5 cells and CD133-Huh7 cells decreased, membrane-bound MICA increased, and soluble MICA production decreased. CD133si-PLC/PRF/5 cells and CD133-Huh7 cells are both sensitive to NK activity, which depends on the expression level of membrane-bound MICA, while HCC cells expressing CD133 are not. $\begin{array}{lll}\text { NK } & \text { The immune } & \text { CD8 }{ }^{+} \text {T cells and NKT cells promote NASH and HCC by interacting with hepatocytes, but not myeloid } \\ \text { cells } & \text { mechanism } & \text { cells. NKT cells mainly cause steatosis by secreting light, and CD8 }{ }^{+} \text {and NKT cells synergistically induce }\end{array}$ 
TABLE 2 | (Continued) The immune cells in TME: NK cells.

\begin{tabular}{|c|c|c|c|}
\hline Cells & $\begin{array}{l}\text { The research } \\
\text { direction }\end{array}$ & Result & Reference \\
\hline & & $\begin{array}{l}\text { liver damage. Hepatocyte LT } \beta \text { R and typical NF-kB signals promote the transformation of NASH to HCC, } \\
\text { indicating that different molecular mechanisms determine the development of NASH and HCC. }\end{array}$ & \\
\hline $\begin{array}{l}\text { NK } \\
\text { cells }\end{array}$ & $\begin{array}{l}\text { The immune } \\
\text { mechanism }\end{array}$ & $\begin{array}{l}\text { In-depth studies of the immune landscape show that regulatory T cells }(T) \text { and CD8 resident memory } \\
\text { T cells }(T) \text { are enriched in hbv-related HCC, while Tim-3CD8 T cells and CD244 natural killer cells are in non- } \\
\text { virus-related HCC In the enrichment. }\end{array}$ & Lim et al. (2019) \\
\hline $\begin{array}{l}\text { NK } \\
\text { cells }\end{array}$ & $\begin{array}{l}\text { The immune } \\
\text { mechanism }\end{array}$ & $\begin{array}{l}\text { Senescence monitoring requires the recruitment and maturation of CCR2 bone marrow cells, while CCR2 } \\
\text { ablation induces HCC growth. In contrast, HCC cells inhibit the maturation of recruited myeloid precursors, } \\
\text { which promote mouse HCC growth and deteriorate the prognosis and survival of human HCC patients by } \\
\text { inhibiting NK cells. }\end{array}$ & Eggert et al. (2016) \\
\hline $\begin{array}{l}\text { NK } \\
\text { cells }\end{array}$ & $\begin{array}{l}\text { The immune } \\
\text { mechanism }\end{array}$ & $\begin{array}{l}\beta \text {-glucosylceramide alleviates immunologically incongruent disease by altering the plasticity of NKT } \\
\text { lymphocytes and may be involved in the "fine-tuning" of the immune response. }\end{array}$ & Zigmond et al. (2007) \\
\hline $\begin{array}{l}\text { NK } \\
\text { cells }\end{array}$ & $\begin{array}{l}\text { The immune } \\
\text { mechanism }\end{array}$ & $\begin{array}{l}\text { Proliferating immune cells, mainly NK cells and T cells, were present in the patient's long-lived tumor and } \\
\text { consisted only of tumor cells lacking proliferation in the region. The density of NK cells and CD8+T cells was } \\
\text { positively correlated with tumor cell apoptosis and negative proliferation. }\end{array}$ & Chew et al. (2010) \\
\hline $\begin{array}{l}\text { NK } \\
\text { cells }\end{array}$ & immunotherapy & $\begin{array}{l}\text { GS-9620 treatment is associated with a reversible increase in serum liver enzymes and thrombocytopenia, } \\
\text { and induction of intrahepatic CD8 }{ }^{+} \mathrm{T} \text { cells, NK cells, B cells, and interferon response transcriptional } \\
\text { signaling. }\end{array}$ & Menne et al. (2015) \\
\hline $\begin{array}{l}\text { NK } \\
\text { cells }\end{array}$ & $\begin{array}{l}\text { The immune } \\
\text { mechanism }\end{array}$ & $\begin{array}{l}\text { Fibrosis is a way to enhance the occurrence of HCC. Changes in fibrosis also regulate the activity of } \\
\text { inflammatory cells in the liver and reduce natural killing, which is generally helpful for tumors to monitor the } \\
\text { activity of natural killer T cells. These pathways work in conjunction with inflammatory signals, including } \\
\text { telomerase activation and the release of reactive oxygen species, ultimately leading to cancer. }\end{array}$ & $\begin{array}{l}\text { Zhang and Friedman, } \\
\text { (2012) }\end{array}$ \\
\hline $\begin{array}{l}\text { NK } \\
\text { cells }\end{array}$ & immunotherapy & $\begin{array}{l}\text { AdCMVmCD4OL therapy can induce strong lymphocyte infiltration in tumor tissues and increase the } \\
\text { apoptosis of malignant cells. The observed anti-tumor effect is mediated by CD8 }{ }^{+} T \text { cells and is related to } \\
\text { increased serum levels of interleukin (IL)-12 and enhanced natural killer (NK) activity. }\end{array}$ & Schmitz et al. (2001) \\
\hline $\begin{array}{l}\text { NK } \\
\text { cells }\end{array}$ & $\begin{array}{l}\text { The immune } \\
\text { mechanism }\end{array}$ & $\begin{array}{l}\text { The activation of } \beta \text {-catenin in hepatocytes can change the liver microenvironment and lead to the specific } \\
\text { targeting of iNKT cells. The activation of } \beta \text {-catenin in hepatocytes triggers the pro-inflammatory process } \\
\text { related to the activation of NF- } \kappa \mathrm{B} \text {. In the process of liver inflammation induced by } \beta \text {-catenin, iNKT cells } \\
\text { showed anti-inflammatory properties. In HCC induced by } \beta \text {-catenin, iNKTs and LECT2 are the key cellular } \\
\text { and molecular effectors to control tumor progression. }\end{array}$ & Anson et al. (2012) \\
\hline $\begin{array}{l}\text { NK } \\
\text { cells }\end{array}$ & $\begin{array}{l}\text { The immune } \\
\text { mechanism }\end{array}$ & AdCMVIL-12 can activate natural killer cells (NK) and inhibit angiogenesis. & Barajas et al. (2001) \\
\hline $\begin{array}{l}\mathrm{NK} \\
\text { cells }\end{array}$ & $\begin{array}{l}\text { The immune } \\
\text { mechanism }\end{array}$ & $\begin{array}{l}\text { Gene transfer of angiostatin inhibited tumor angiogenesis and enhanced NK cell infiltration, while B7H3 } \\
\text { therapy activated } \mathrm{CD}^{+} \text {and NK cells and increased their infiltration into the tumor, and enhanced } \\
\text { circulating IFN- } \gamma \text { levels. }\end{array}$ & Ma et al. (2007) \\
\hline
\end{tabular}

example, In mice, combining DC vaccination and PD-L1 inhibitor treatment can result in longer overall life, reduced tumor volume, and increased tumor cell apoptosis. As a new therapy method for HCC, combined treatment with DC vaccination and PD-L1 inhibitor may offer promising results (Teng et al., 2020). Ali et al. 's research clarified that the combination of PEI or RFTA with active antigen-specific immunotherapy using DCS is a promising approach to induce a sustained anti-tumor immune response aimed at reducing tumor recurrence and metastasis in patients with HCC. Table 3 summarizes the current role of DC cells in HCC.

\section{M1-Polarized Macrophages}

Another important type of immune cell in TME is macrophages derived from circulating monocytes, which can generally be divided into M2 polarization and M1 polarization (Figure 2). M1-polarized macrophages, for example, can create proinflammatory cytokines and reactive oxygen species/nitrogen to prevent the formation and progression of malignancies (Aras and Zaidi, 2017). There are limited investigations on the function of M1-polarized macrophages in HCC at the moment. Studies have shown that M1-polarized macrophages in the S3 subclass in HCC increased, and the prognosis was good. Memory B cells, Total B cells, M1 macrophages and T follicle helper cells, were linked with strong total immune cell infiltration into HCC, whereas resting mast cells, neutrophils, and NK cells were associated with poor infiltration (Rohr-Udilova et al., 2018). Table 4 summarizes the current role of M1-polarized macrophages in HCC.

\section{TUMOR-PROMOTING IMMUNE CELLS}

In the immune microenvironment of HCC, some cells could promote the occurrence and development of HCC, and we will review them one by one.

\section{Regulatory T cells(Tregs)}

Tregs play a vital role in immunological homeostasis and immune self-tolerance, and they can express the $\mathrm{CD} 4^{+}$marker and the Foxp3 marker (Samstein et al., 2012). Foxp3+ Treg acts as a switch for all levels of immune response, and its effects appear to be two-sided. First, Treg can inhibit harmful immune responses and thus inhibit the occurrence of autoimmune diseases (Berod 
TABLE 3 | The immune cells in TME: Dendritic cells.

\begin{tabular}{|c|c|c|}
\hline Cells & $\begin{array}{l}\text { The research } \\
\text { direction }\end{array}$ & Result \\
\hline $\begin{array}{l}\text { Dendritic } \\
\text { cells }\end{array}$ & immunotherapy & $\begin{array}{l}\text { The combination of DC vaccine and PD-L1 inhibitor resulted in longer overall survival, smaller tumor size, } \\
\text { and higher tumor cell apoptosis rate in mice. The combination of DC vaccine and PD-L1 inhibitor may } \\
\text { have broad prospects as a new therapeutic strategy for HCC. }\end{array}$ \\
\hline $\begin{array}{l}\text { Dendritic } \\
\text { cells }\end{array}$ & $\begin{array}{l}\text { The immune } \\
\text { mechanism }\end{array}$ & $\begin{array}{l}\text { XCL1-GPC3 cells chemically attract murine XCR1CD8a dendritic cells (DCs) and human XCR1CD141 } \\
\text { DCs, and promote their IL12 production. }\end{array}$ \\
\hline $\begin{array}{l}\text { Dendritic } \\
\text { cells }\end{array}$ & $\begin{array}{l}\text { The immune } \\
\text { mechanism }\end{array}$ & $\begin{array}{l}\text { A more severe reduction in basal OCR was observed in tumor-derived DCs exposed to AFP due to } \\
\text { down-regulation of cytochrome C oxidase. The expression of PGC1- } \alpha \text { in circulating medullary DC in } \\
\text { HCC patients was decreased, and the ability to stimulate the function of antigen-specific effector was } \\
\text { impaired, indicating the negative effect of AFP on DC metabolism. }\end{array}$ \\
\hline Dendritic & The immune & AFP down-regulated CD1 on DC, but had little effect on NKT cell activation. \\
\hline
\end{tabular}

cells mechanism

Dendritic The immune

cells mechanism

Dendritic The immune

cells mechanism

Dendritic immunotherapy

cells

Dendritic immunotherapy

cells

Dendritic immunotherapy

cells

ing

Dendritic immunotherapy

cells

Dendritic The immune

cells mechanism

Dendritic The immune

cells mechanism

Dendritic The immune

cells mechanism

Dendritic immunotherapy

cells

\begin{tabular}{|c|c|}
\hline $\begin{array}{l}\text { Dendritic } \\
\text { cells }\end{array}$ & immunotherapy \\
\hline $\begin{array}{l}\text { Dendritic } \\
\text { cells } \\
\text { Dendritic } \\
\text { cells }\end{array}$ & $\begin{array}{l}\text { The immune } \\
\text { mechanism } \\
\text { immunotherapy }\end{array}$ \\
\hline $\begin{array}{l}\text { Dendritic } \\
\text { cells }\end{array}$ & $\begin{array}{l}\text { The immune } \\
\text { mechanism }\end{array}$ \\
\hline $\begin{array}{l}\text { Dendritic } \\
\text { cells } \\
\text { Dendritic } \\
\text { cells }\end{array}$ & $\begin{array}{l}\text { The immune } \\
\text { mechanism } \\
\text { immunotherapy }\end{array}$ \\
\hline
\end{tabular}

Dendritic immunotherapy

cells

Dendritic immunotherapy

cells

Dendritic The immune

cells mechanism

DC-CIK cells can inhibit the growth of HCC and LCSC in vitro and in vivo, and the most successful DCtriggered cell killing activity can be achieved through their LCSC antigen loading.

MIP-10 enhances the antitumor activity of the DC/tumor fusion vaccine by alleviating the immunosuppressive tumor environment.

The use of nifurazine and DC-loaded TCL significantly increased the survival rate, inhibited tumor growth and promoted anti-tumor immune response in HCC mice implanted in situ.

Overexpression of IL-12 induced by adenovirus vector can effectively immunize DC. Intratumor but not systemic injection of activated IL-12-DC is essential for effective tumor regression. Improved immunotherapy with IL-12-DC represents a promising approach for the treatment of HCC.

$\beta-\mathrm{GC}$ activated mouse liver NKT cells and enhanced the anti-tumor activity of PAD-HBsAg-DC. $\beta$-GC may act as an effective innate immune enhancer to enhance the antitumor effect of PAD-HBsAg-DC vaccine.

Camory may play an important role in the development and progression of $\mathrm{HCC}$ through recruitment of DC and NK cells.

Electroporation of GPC-3 mRNA is an effective method for antigen-carrying monocytes to generate DCs because they produce functional GPC-3 reactive T cells in vitro.

Immature DCs(IMDCs) derived from human monocytes were fully mature after effective phagocytosis of dying cells, and showed significant proliferation and cytotoxicity to HLA-matched HEPG (2) cells in autologous peripheral blood monocytes (PBMC).

Secondary lymphoid tissue chemokines (SLC) are strongly expressed in secondary lymphoid organs. It has the ability to promote dendritic cell (DC) and T cell chemotaxis, making it a promising candidate for cancer therapy.

AdvHAFP-transduced DCs activate higher frequencies of Th1 CD4 responses to AFP in healthy donors and AFP positive HCC patients. Importantly, when activated by adenovirus-engineered DC, the cytokine expression profile of CD4+T cells was biased towards the production of interleukin-2 and interferon- $\gamma$, which has therapeutic implications for vaccination work.

Dendritic cells transfected with total HCC mRNA stimulated an antigen-specific cytotoxic T cell response capable of recognizing and killing autologous tumor cells in vitro.

Impairment of MDCs produced by IL-12 may result in impaired stimulation of naive T cells, suggesting that targeted IL-12 therapy may enhance tumor-specific immune responses in patients with HCC.

The combination of PEI or RFTA with active antigen-specific immunotherapy using DCS is a promising approach to induce a sustained anti-tumor immune response aimed at reducing tumor recurrence and metastasis in patients with HCC.

The phenotypic and functional deficits of PBMC-derived DCs in LC and HCC patients may play a key role in HBV infection and HCC immune escape. After tumor is stimulated by antigen, DC function can be enhanced in LC patients.

Ad-HBsAg-transduced DCs stimulated a strong cytotoxic T lymphocyte (CTL) response to HBsAgexpressing tumor cells and protected mice from lethal tumor attack.

At concentrations up to $20 \mu \mathrm{g} / \mathrm{mL}$, AFP did not alter the in vitro generation, maturation and T cell stimulation of DC. Higher AFP concentration ( $>20 \mu \mathrm{g} / \mathrm{ml}$ ) led to phenotypic changes in DC without impair its ability to stimulate CD4 ${ }^{+}$T cells. Independent of serum AFP levels, the frequency and function of DC and AFP-specific T cells did not decrease in HCC patients.

Autologous DCs containing the HCA587 protein can induce specific T cell responses in healthy individuals by in vitro stimulation, and HCA587 is a good candidate for the development of a proteinbased therapeutic DC tumor vaccine for the treatment of HCC patients.

DCs transfected with MAGE-1 gene can induce higher cytotoxicity of SMMC7721 in vitro, suggesting that this transgenic DC may have the potential to induce specific antitumor activity and be used as a novel HCC vaccine.

Reference

Teng et al. (2020)

Chen et al. (2020)

Santos et al. (2019)

Li et al. (2019a)

Yang et al. (2018b)

Hu et al. (2017)

Zhao et al. (2017b)

Vogt et al. (2014)

Long et al. (2013)

Lin et al. (2011)

O'Beirne et al. (2010)

Xing et al. (2009)

Liang et al. (2007)

Evdokimova et al.

(2007)

Peng et al. (2006)

Ormandy et al. (2006)

Ali et al. (2005)

Wong et al. (2005)

Qiu et al. (2005)

Ritter et al. (2004)

Li et al. (2004)

Liu et al. (2001)

Decline in DC function and normal T cell response were observed in HBV-infected HCC patients, suggesting that the low function of DC is related to the pathogenesis of HBV or HCV-infected HCC. 


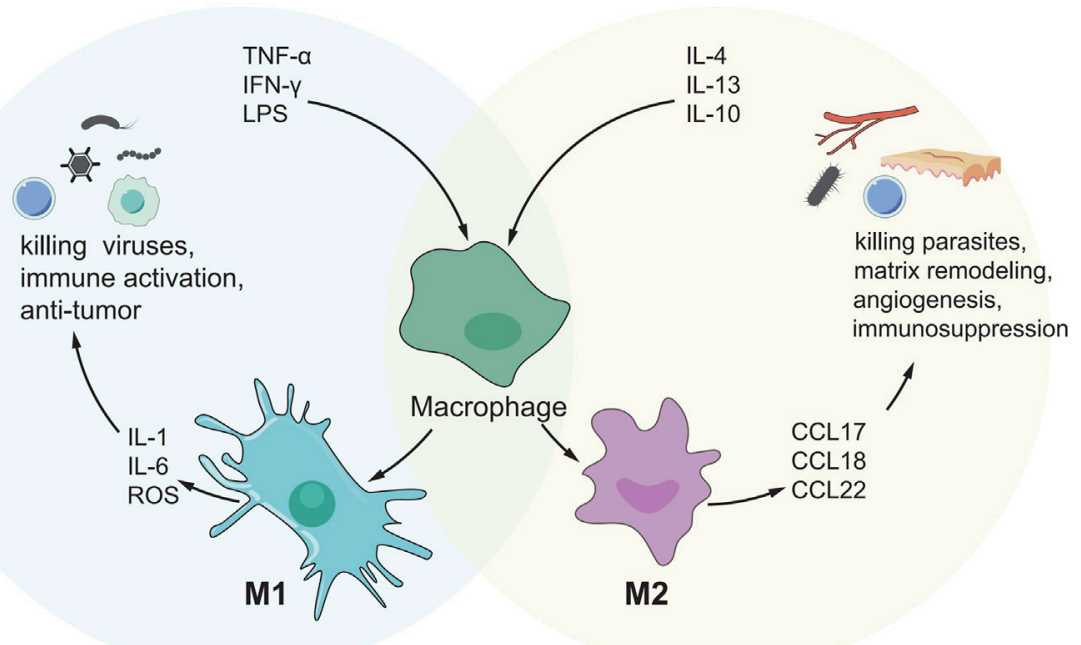

FIGURE 2 | M1/M2 model of macrophage activation. M1 cells exert an inflammatory phenotype and are involved in killing bacteria, viruses and tumor cells, while M2 cells are involved in killing encapsulated parasites, immunosuppression, angiogenesis, etc.

TABLE 4 | The immune cells in TME: M1-polarized macrophages.

Cells

The research

direction

M1-polarized

macrophages

M1-polarized

macrophages
The immune mechanism

The immune mechanism
Result

The number of M1-polarized macrophages in the S3 subclass in HCC was increased, and the prognosis was good. Strong total immune cell infiltration into HCC was associated with total B cells, memory B cells, T follicle helper cells, and M1 macrophages, while weak infiltration was associated with resting NK cells, neutrophils, and resting mast cells.

Conditionalized media from M1 macrophages promoted HCC cell migration and induced activation of NF- $\mathrm{KB}$ and FAK signal transduction. Activation of Bay 11-7,802 and NF- $\mathrm{B}$ and FAK pathways eliminated HCC cell induced migration, suggesting that M1-like TAM has a metastatic role in HCC. et al., 2012). Second, Treg suppresses protective immune responses against invading pathogens or tumors, leading to further progression of the disease (Sakaguchi et al., 2010). How does Treg play a role in tumors, including how does Treg infiltrate and metastasize to tumor sites or how does Treg help tumors evade immune monitoring, has become a hot research topic in recent years. Many ideas have been put forward. Tregs were found in much higher numbers in HCC patients than in healthy controls. In addition, patients with high Treg(III) levels after TACE had a significantly lower progressionfree survival than patients with low Treg(III) levels after TACE (Park et al., 2020). Other studies have shown that tumor Treg upregulated the expression of the glucocorticoid-induced tumor necrosis factor receptor (GITR). Treatment with soluble GITR ligand (GITRL) reduced inhibition caused by activated tumor infiltrating Treg and restored $\mathrm{CD}^{+} \mathrm{CD} 25-\mathrm{T}$ cell proliferation and cytokine production. (Pedroza-Gonzalez et al., 2013). In addition to that, the proportion of Tregs cells in HCC patients was significantly higher than that in healthy and cirrhosis controls, and was related to various clinical indicators of HCC patients. In HCC patients with BCLC stage $\mathrm{C}$, the proportion of
Treg cells was more pronounced than in BCLC stage B patients. One to 2 weeks after surgery, the fraction of Treg cells was much lower than before GSMS-TACE. Three to 5 weeks following surgery, the proportion of Treg cells continued to decline (Ren et al., 2021). Table 5 summarizes the most credible studies related to the role of Treg in HCC.

\section{Myeloid-Derived Suppressor cells}

MDSC is thought to be a cancer-promoting immune cell in the HCC tumor microenvironment and was discovered a decade ago (Gabrilovich et al., 2007). MDSC is divided into granulocyte or multinuclear MDSC(PMN MDSC) and mononuclear MDSC(M-MDSC) (Veglia et al., 2018). MDSCs enhance angiogenesis by producing vascular endothelial growth factor (VEGF), actuator 2 and MMP9. They can also cause cancer cells to migrate to endothelial cells and encourage metastasis (Zhou et al., 2018a). MDSC also suppresses T cell activity by secreting immunosuppressive cytokines, inducible nitric oxide synthase, and argininase (Gabrilovich et al., 2012; Gabrilovich, 2017). MDSCs can have a dual influence on immune cells via distinct methods. B cells, T cells, DCs and NK cells, are all inhibited by 
TABLE 5 | Tumor-promoting immune cells: Regulatory T cells.

$\begin{array}{ccc}\text { Cells The research } & \text { Result } \\ \text { direction } & \text { Reference }\end{array}$

Treg immunotherapy

Treg The immune mechanism

Treg The immune mechanism

Treg immunotherapy

Treg The immune mechanism

Treg The immune mechanism

Treg Prognostic marker

Treg The immune mechanism

Treg The immune mechanism

Treg Prognostic marker

Treg The immune mechanism

Treg immunotherapy

Treg immunotherapy

Treg immunotherapy

Treg immunotherapy

Treg The immune mechanism

Treg The immune mechanism

Treg Prognostic marker

Treg immunotherapy

Treg immunotherapy

Treg The immune mechanism

Treg The immune mechanism

Treg immunotherapy

Treg immunotherapy
The proportion of Treg cells in BCLC stage C HCC patients was higher than that in BCLC Stage B patients, and the proportion of Treg cells was significantly lower than that before GMS-TACE $1 \sim 2$ weeks after surgery. The percentage of Treg cells continued to decrease 3-5 weeks after surgery.

Tumor progression is associated with the deep depletion of tumor antigen-specific CD8T cells and the accumulation of PD-1 CD8T cells and Treg cells.

At a non-cytotoxic concentration, resveratrol inhibited differentiation of CD8CD122 Treg from CD8CD122 T cells.

The baseline reduction in the number or frequency of FOXP3Tregs, MDSCs, and exhausted T cells was significantly greater after tivozanib treatment. In addition, a larger increase in CD4T cells: Treg ratio after tivozanib treatment compared with sorafenib was associated with a significant improvement in OS.

Long-term intake of ethanol can enrich HBV-enhanced abnormal lipid metabolism through HBx/Swaell1/ arachidonic acid signaling and activate Treg in mice.

Lower CD8 T cell density and higher Foxp3 Tregs and immune checkpoint strength in intrahepatic cholangiocarcinoma (ICC) components compared to HCC components may indicate a stronger immune escape capability of ICC.

The frequency of Tregs was significantly higher in HCC patients than in healthy controls. In addition, patients with high Treg (III) after TACE had a significantly reduced progression-free survival compared to patients with low Treg (III) after TACE.

Regulatory CD4/CD25/Foxp3 T cells (Tregs) were activated by transcriptional reprogramming of HCC parent cells in MacroH2A1 KD conditioned medium. Loss of MacroH2A1 in HCC cells drives proliferation and avoidance of immune surveillance by cancer stem cells.

Treg-induced inhibition of IFN- $\gamma$ secretion is partially prevented by neutralizing PD- 1 and PD-L1 antibodies in HCC patients. In HCC, peripheral blood Tregs upregulate checkpoint inhibitors and promote systemic immune dysfunction and antitumor activity through several inhibitory pathways, presumably contributing to the development of tumors at a young age.

Patients with an increased T-effector/Treg ratio before treatment showed significant improvement in OS. Overexpression of IncRNA FENDRR and down-regulated miR-423-5p reduced cell proliferation and tumorigenicity, and promoted apoptosis of HCC cells, thereby regulating Treg-mediated immune escape of HCC.

The hypoxic environment induces tumor immunosuppression by attracting TREM-1 TAMs of CCR6. Foxp3 Treg, and TREM-1 TAMs make HCC resistant to PD-L1 therapy

After sorafenib alone and in combination, plasma SMet was elevated and TTP and OS shortening were associated with increased Tregs and CD56 natural killer (NK) cells.

Sunitinib treatment induces an anti-tumor immune response by significantly reducing Treg frequency, TGF- $\beta$ and IL-10 production by Treg, and protecting TAS CD8 T cells from HCC infection

Newly produced STAT3-blocked whole-cell HCC vaccines reduced production of Treg as well as production of TGF- $\beta$ and IL-10.

LNC-EGFR specifically binds to EGFR and prevents its interaction with c-CBL and is ubiquitinated by C-CBL, which stabilizes and enhances the activation of its own and its downstream AP-1/NF-AT1 axis, thus causing EGFR expression. LNC-EGFR has been associated with immunosuppressive status and cancer by promoting Treg cell differentiation.

Overexpression and activation of YAP-1 in HCC T cells can promote differentiation of Treg through enhanced transcription of TGFbR2, thereby inducing immunosuppression.

CXCL10/CXCR3 signals were upregulated after liver graft injury, directly inducing the mobilization and recruitment of Tregs during transplantation, and further promoting the recurrence of $\mathrm{HCC}$ after transplantation.

After treatment with sorafenib, the ratio of CD4CD127PD-1 T effector cells to CD4FoxP3PD-1 Treg was significantly increased. The increased frequency of CD4CD127 T effector cells in posttreated samples was significantly correlated with OS.

Sunitinib-mediated tumoricidal effect, Treg inhibition and antibody-mediated PD-1 blocking synergistic effect can effectively inhibit tumor growth and activate anti-tumor immunity.

The secreting of cancerous TGF- $\beta 1$ may increase Tregs, while TGF- $\beta 1$ knockdown may impair immunosuppression in the tumor microenvironment by decreasing Tregs.

Intra-tumor combination of SLC and anti-CD25 mAb is an effective method for the treatment of HCC, which is related to the change of tumor microenvironment and the systematic optimization percentage of Treg, $\mathrm{CD} 8^{+} \mathrm{T}$ cells and $\mathrm{CD} 4^{+} \mathrm{T}$ cells in peripheral immune organs.

Sorafenib treatment can reduce the number of Treg by inhibiting the proliferation of Treg and inducing its apoptosis. In addition, sorafenib inhibits the function of Tregs, characterized by reduced expression of functionally important Treg-related molecules and impaired inhibition. Sorafenib treatment alleviated noncellular autonomous inhibition of the tumor microenvironment mediated by Treg, leading to an effective anti-tumor immune response.

The subpharmacological doses of sorafenib had different effects on $T$ cell subsets, selectively increasing Teff activation while blocking Treg function.
Ren et al. (2021)

Tipton et al. (2011)

Zhang et al. (2020)

Kalathil et al. (2020)

Liu et al. (2020a)

Zheng et al. (2020b)

Park et al. (2020)

Lo Re et al. (2020)

Langhans et al. (2019)

Kalathil et al. (2019)

Yu et al. (2019a)

Wu et al. (2019a)

Goyal et al. (2019)

Liu et al. (2017)

Han et al. (2017)

Jiang et al. (2017b)

Fan et al. (2017)

Li et al. (2016)

Kalathil et al. (2016)

Li et al. (2017)

Wang et al. (2016)

Chen et al. (2013)

Chen et al. (2014)

Cabrera et al. (2013)

(Continued on following page) 
TABLE 5 | (Continued) Tumor-promoting immune cells: Regulatory T cells.

\begin{tabular}{|c|c|c|c|}
\hline Cells & $\begin{array}{l}\text { The research } \\
\text { direction }\end{array}$ & Result & Reference \\
\hline Treg & $\begin{array}{l}\text { The immune } \\
\text { mechanism }\end{array}$ & $\begin{array}{l}\text { Tumor Treg upregulated glucocorticoid-induced tumor necrosis factor receptor (GITR) expression. } \\
\text { Treatment with soluble GITR ligand (GITRL) induced a reduction of inhibition mediated by activated tumor } \\
\text { infiltrating Treg and restored the proliferation and cytokine production of CD4 }{ }^{+} \text {CD25-T cells. }\end{array}$ & $\begin{array}{l}\text { Pedroza-Gonzalez et al. } \\
\text { (2013) }\end{array}$ \\
\hline Treg & The prognosis & $\begin{array}{l}\text { Elevated FOXP3 (+) Tregs may represent a prognostic marker in patients with early HCC. The natural } \\
\text { history of } \mathrm{CHB} \text { influences the density of tumor infiltrate Treg in patients with chronic hepatitis B virus } \\
\text { infection. }\end{array}$ & Wang et al. (2012) \\
\hline Treg & $\begin{array}{l}\text { The immune } \\
\text { mechanism }\end{array}$ & $\begin{array}{l}\text { The increased frequency of CD45Ro + subsets in } \mathrm{CD}^{+} \mathrm{CD} 25(\mathrm{HIGH}) \text { Tregs in } \mathrm{HCC} \text { patients may } \\
\text { cooperate with the establishment of an immunosuppressive environment that induces tolerance of } \\
\text { plasmocyte like DCs, thereby promoting the development of } \mathrm{HCC} \text {. }\end{array}$ & Takata et al. (2011) \\
\hline Treg & $\begin{array}{l}\text { The immune } \\
\text { mechanism }\end{array}$ & $\begin{array}{l}\text { The tumor-associated MVARPHI may trigger an increase in the number of Foxp3 }(+) \text { Treg populations in } \\
\text { tumors, thereby promoting the development of HCC. }\end{array}$ & Zhou et al. (2009) \\
\hline
\end{tabular}

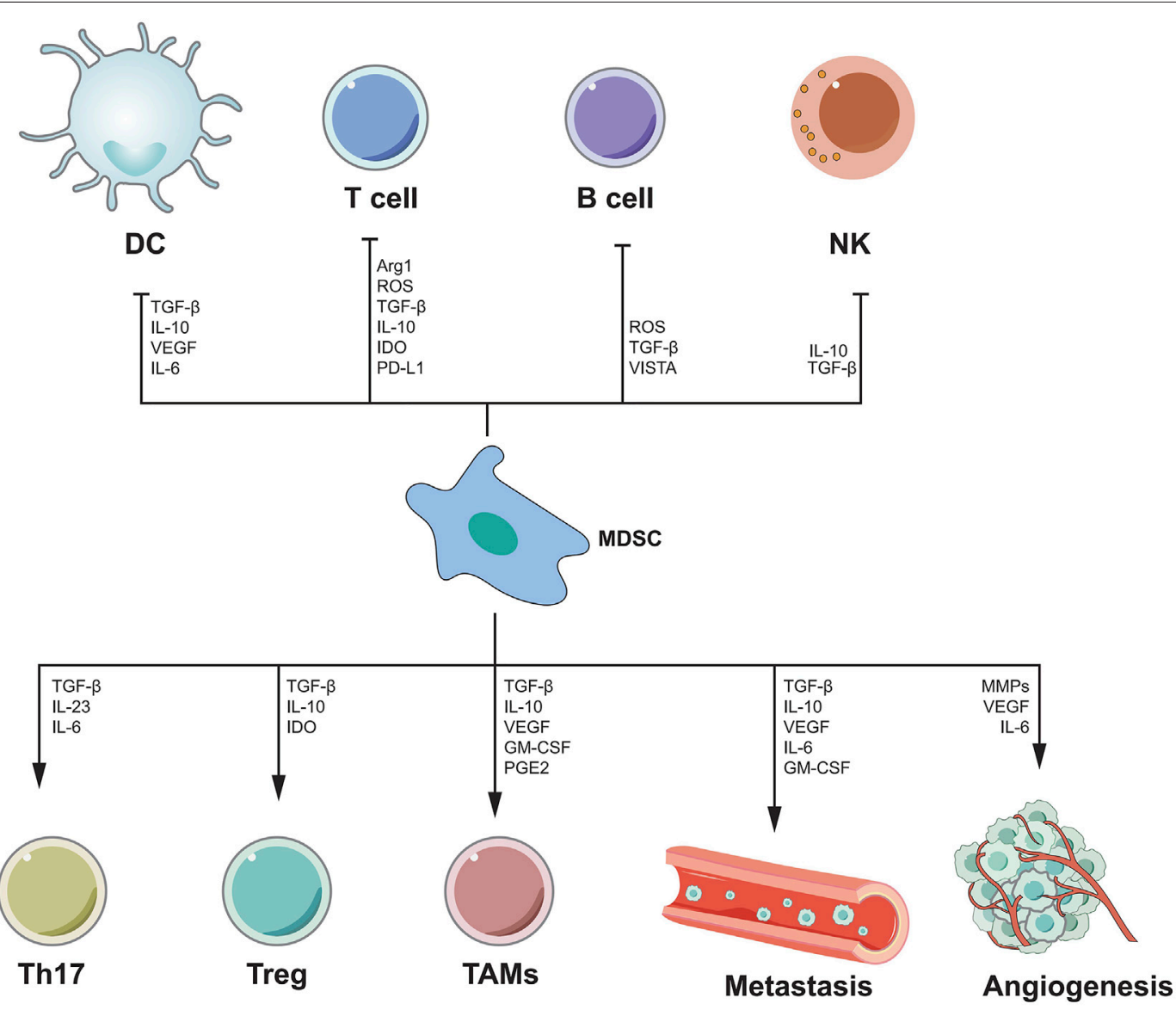

FIGURE 3 | The mechanism of MDSC-mediated immunosuppression. MDSC inhibits the functions of DC, T cells, B cells and NK cells by secreting various cytokines, while promoting the functions of Th17, Treg, TAMs cells, and can promote angiogenesis and metastasis.

MDSCs. MDSCs, on the other hand, can stimulate Th17 cells, Tregs, and TAMs, as well as tumor angiogenesis and metastasis (Figure 3). There has been a great deal of research on the processes through which MDSC supports the advancement of HCC, and many therapeutic pathways have been developed for MDSC as a target of HCC. For example, myeloid-derived suppressor cells (MDSCs) are drawn to the tumor microenvironment by PIWIL1-overexpressed HCC cells. MDSCs consumption reduced the proliferation and growth of PIWIL1-overexpressed HCC tumors. Complement C3 stimulates HCC cell secretion via PIWIL1 and mediates the contact between HCC cells and MDSC via p38 MAPK activation in MD38, and then 
TABLE 6 | Tumor-promoting immune cells: Myeloid-derived suppressor cells.

\begin{tabular}{llll}
\hline Cells The research direction Result & References
\end{tabular}

MDSCs The immune mechanism

MDSCs The immune mechanism

MDSCs immunotherapy

MDSCs immunotherapy

MDSCs immunotherapy

MDSCs The immune mechanism

MDSCs immunotherapy/The immune mechanism

MDSCs Prognostic marker

MDSCs immunotherapy

MDSCs immunotherapy

MDSCs The immune mechanism

MDSCs The immune mechanism

MDSCs The immune mechanism

MDSCs immunotherapy

MDSCs The immune mechanism

MDSCs immunotherapy

MDSCs The immune mechanism
The heterozygous loss of SPTBN1 significantly upregulated the liver expressions of IL-1a, IL-1 $\beta$ and Lin et al. (2021) IL-6, and increased the proportion of myeloid inhibitory cells (MDSC) and CD4CD25Foxp3 regulatory T cells (Foxp3Treg) in liver, which promoted the occurrence of HCC in DDC-fed mice. MDSCs contribute to tumor progression under psychological stress, chronic binding stress Cao et al. (2021) significantly promotes the growth of $\mathrm{HCC}$, and MDSCs are mobilized from bone marrow to spleen and tumor sites. Also, the $\beta$-adrenergic signaling cascade plays a key role in the mobilization and recruitment of MDSC under chronic confinement stress.

Icaritin blocks MDSC production by blocking the attenuation of $\mathrm{EMH}$, thereby inhibiting the immunosuppressive effect of the tumor, thereby triggering an anti-tumor immune response.

Therefore, Icaritin can be used as a new adjuvant or even as an independent therapeutic agent for the effective treatment of HCC.

PIWIL1 overexpressed HCC cells attract myeloid suppressor cells (MDSCs) to the tumor microenvironment. MDSCs consumption reduced the proliferation and growth of HCC tumors overexpressed by PIWIL1. Complement C3 induces the secretion of HCC cells through PIWIL1, mediates the interaction between HCC cells and MDSC by activating the P38 MAPK signal in MD38, and then initiates the expression of the immunosuppressive cytokine IL10.

After tivozanib treatment, the baseline number or frequency of FOXP3treg, MDSC, and exhausted T cells decreased significantly more. This may help identify patients who may benefit from c-kit/SCF antagonism and provide guidance for improving the efficacy of tivozanib in combination with immunotherapy.

$\mathrm{CD}^{+} \mathrm{T}$ cells, MDSCs, and M2 macrophages were particularly increased in the tumorigenic liver of NCoA $5 \pm$ male mice. NCoA5 deficiency promotes a unique hepatic tumorigenetic microenvironment through p21WAF1/CIP1 overexpression, which metformin reverses. HSC promoted migration of MDSC through the SDF-1/CXCR4 axis. Pretreatment of MDSC with CXCR4 inhibitors or injection of SDF-1 knockout HSC inhibited migration of MDSC to the spleen and liver of tumor-bearing mice.

Patients with an increased T-effector/Treg ratio before treatment showed significant improvement in OS. ERK + FLT-3+ Treg and MDSCs were significantly reduced after sorafenib treatment. An increase in baseline Flt-3+ p-ERK + MDSC was associated with a patient survival benefit.

Conclusion High baseline CD4 ${ }^{+} \mathrm{T}$ effector/Treg ratio may be an important biomarker for prognosis in $\mathrm{HCC}$.

CCR2 antagonists inhibited the infiltration of TAM and MDSC and delayed tumor growth in tumors of mice expressing A3b and A3b. Mechanically, upregulation of A3B in HCC inhibs the global abundance of $\mathrm{H} 3 \mathrm{~K} 27 \mathrm{me} 3$ and reduces the presence of H3K27me3 on the chemokine $\mathrm{Ccl} 2$ promoter by interacting with the multicomb repressor complex 2(PRC2), thus recruiting large amounts of TAM and MDSC.

Activated HSC induces mononuclear intrinsic p38 MAPK signaling, which triggers enhancer reprogramming for M-MDSC development and immunosuppression. Treatment with p38 MAPK inhibitors eliminated HSC-M-MDSC crosstalk to prevent HCC growth. Combined with I-BET762 suppressed patient-derived M-MDSC, combined with anti-PD-L1 therapy synergically enhanced $\mathrm{TIL}$, resulting in tumor eradication and prolonged survival in a fibrotic HCC mouse model. RIP3 knockdown results in an increase in MDSCs and a decrease in interferon $\Delta$ - positive (IFN- $\gamma$ ) clusters of tumor-infiltrating lymphocytes (CD8) differentiated into 8 positive (CD8) cells in HCC tissue, thus promoting immune escape and HCC growth in immunologically competent mice. By down-regulating the expression of IDO1, the HS donor induced T effector cells and inhibited MDSCs, and effectively restricted the tumor development of H22 HCC tumor-bearing mice. March-derived suppressor cells (MDSCs) and tumor-associated macrophages (TAM) from the tumor microenvironment contribute to the suppression of the CD8 T cell response.

Adoptive transfer of CIK to tumor-bearing mice induced an increase in inflammatory mediators (e.g., CX3CL1, IL-13) and tumor-infiltrating MDSC in the tumor microenvironment, and MDSCs effectively inhibited the cytotoxic activity of CIKs in vitro. In contrast, treatment with PDE5 inhibitors reversed MDSC inhibition by Arg1 and NOS, while systemic treatment with PDE5 inhibitors prevented MDSC accumulation in the tumor microenvironment after CIK cell treatment and increased its anti-tumor efficacy.

RT/IL-12 significantly reduced the accumulation of tumor-infiltrating myeloid suppressor cells (MDSC) and its inhibitory function by reducing the production of reactive oxygen species Tumor-infiltrating LY6G MDSCs from orthotopic liver tumors treated with sorafenib significantly induced CD4+T cells expressing IL-10 and TGF- $\beta$ and down-regulated the cytotoxic activity of CD8 T cells. IL-6 protects LY6G MDSC against sorafenib induced cell death in vitro. The combination of anti-LY6G antibody or anti-IL-6 antibody and sorafenib significantly reduced the cell proportion of LY6G MDSCs in orthotopic liver tumors, enhanced the proliferation of T cells, and synergically improved the therapeutic effect of sorafenib.

Tumor-infiltrating CD11BCD33HLA-DR MDSCs in HCC patients can effectively inhibit autologous CD8T cell proliferation. Concordant overexpression of CCRK and MDSC markers (CD11b/CD33)

(Continued on following page) 
TABLE 6 | (Continued) Tumor-promoting immune cells: Myeloid-derived suppressor cells.

\begin{tabular}{|c|c|c|c|}
\hline Cells & The research direction & Result & References \\
\hline & & $\begin{array}{l}\text { was positively associated with poorer survival. Hepatocyte CCRK stimulated the } \\
\text { immunosuppressive CD11BCD33HLA-DR MDSC amplification of human peripheral blood } \\
\text { mononuclear cells by up-regulating IL-6. }\end{array}$ & \\
\hline MDSCs & The immune mechanism & $\begin{array}{l}\text { In HCC, hypoxia induces the expression of ENTPD2 on cancer cells, leading to an increase in } \\
\text { extracellular 5'-AMP, which in turn promotes MDSC maintenance by preventing its differentiation. }\end{array}$ & Chiu et al. (2017) \\
\hline MDSCs & immunotherapy & $\begin{array}{l}\text { The tumor suppressive effects of chemerin were associated with metastasis of tumor-infiltrating } \\
\text { immune cells from myeloid suppressor cells (MDSC) to interferon- } \gamma \mathrm{T} \text { cells and decreased tumor } \\
\text { angiogenesis. }\end{array}$ & Lin et al. (2017) \\
\hline MDSCs & The immune mechanism & $\begin{array}{l}\text { TAF-derived cytokines (such as IL- } 6 \text { and SDF-1A) can induce MDSC generation and activation, and } \\
\text { then weaken the human anti-tumor immune response, thus creating favorable conditions for the } \\
\text { development of HCC. }\end{array}$ & Deng et al. (2017) \\
\hline MDSCs & immunotherapy & $\begin{array}{l}\text { The frequency of MDSC before treatment is a prognostic factor for HAIC prevention of HCC. } \\
\text { Patients with lower MDSC frequency also had significantly longer overall survival. }\end{array}$ & $\begin{array}{l}\text { Mizukoshi et al. } \\
\text { (2016) }\end{array}$ \\
\hline MDSCs & immunotherapy & $\begin{array}{l}\text { The frequency of MDSC increased significantly in HCC patients. It is associated with tumor } \\
\text { progression, but not with liver fibrosis or inflammation. }\end{array}$ & Arihara et al. (2013) \\
\hline MDSCs & The immune mechanism & The MDSC-mediated functional inhibition of NK cells mainly depends on NKP30 on NK cells. & Hoechst et al. (2009) \\
\hline
\end{tabular}

initiates the expression of immunosuppressive cytokine IL10. PIWIL1, which is expressed by tumor cells, could be a viable target for the development of new HCC treatments (Wang et al., 2021a). Tumor-infiltrating LY6G MDSCs from orthotopic liver tumors treated with sorafenib dramatically increased CD4 T cells expressing IL-10 and TGF-and decreased CD8 T cell cytotoxicity. In vitro, IL-6 protects LY6G MDSC from sorafenib-induced cell death. Combining sorafenib and anti-IL-6 antibody or anti-LY6G antibody dramatically decreased the cell proportion of LY6G MDSCs in orthotopic liver tumors, synergistically boosted sorafenib's therapeutic efficacy and increased $\mathrm{T}$ cell proliferation (Chang et al., 2018). Icaritin blocks MDSC production by blocking the attenuation of $\mathrm{EMH}$, thereby inhibiting the immunosuppressive effect of the tumor, thereby triggering an anti-tumor immune response. Therefore, Icaritin can be used as a new adjuvant or even as an independent therapeutic agent for the effective treatment of HCC(Tao et al., 2021). In Table 6, we show the relevant role of MDSC in HCC immune microenvironment in recent years.

\section{Cancer-Associated fibroblasts}

CAF is not an immune cell, but it plays an important role in the tumor microenvironment, so we will introduce it in detail here. CAF exists as a prominent component of the tumor stroma between various inflammatory cells and components in the tumor microenvironment (Kalluri, 2016). As a result, CAF possesses functions that normal fibroblasts do not. A vast number of prior studies have demonstrated that CAF plays a critical function in changing the tumor microenvironment and driving the development of a variety of cancers (Jiang et al., 2017a; Zhao et al., 2017a; Deng et al., 2017; Pistore et al., 2017). CAF is also significant in HCC. Many studies have revealed the great role of $\mathrm{CAF}$ in the pathogenesis, progression, prognosis, treatment and other aspects of HCC. CAF-derived cardioctonutrient-like cytokine 1 (CLCF1) has been found in studies to stimulate the release of TGF- $\beta$ and CXCL6 in tumor cells, consequently increasing tumor stem cell development in HCC-TME (Song et al., 2021). Other research have found that $\mathrm{CCN} 2$, EMA, and FAP expression may be involved in the activation of CAF in HCC, resulting in aggressive behavior. The substantial association between EMA-expressing tumor cells and FAPexpressing CAF, as well as their topographical proximity, suggests that there may be interplay between tumor epithelial and stromal cells in the HCC tumor microenvironment (Kim et al., 2014). Table 7 summarizes the current role of CAF in HCC.

\section{M2-Polarized Macrophages}

M2 polarized macrophages, as opposed to M1 polarized macrophages, have anti-inflammatory and pro-tumor actions (Figure 4). M2 macrophages are further differentiated into M2a, M2b, M2c, and M2d subsets. Th2 cytokines such as IL13 and IL-4 can trigger macrophage transformation to the M2A phenotype, whereas TLR and immune complex activation induces $\mathrm{M} 2 \mathrm{~B}$ macrophages, the M2C subtype polarized by IL-10 (Hao et al., 2012; Sica and Mantovani, 2012). Despite the fact that there have been few research on M2-polarized macrophages in HCC, the function of them in the occurrence and development of HCC has been confirmed. According to several studies, arsenite raises miR-15b levels and causes M2 polarization in THP-1 cells. Increased miR-15b in Evs transfer from arsenitetreated THP-1 (AS-THP-1) cells to HCC cells via miR15b. By targeting LATS1, it can reduce Hippo pathway activation while still accelerating the invasion and metastasis of growing HCC cells (Li et al., 2021). The potential therapeutic potential of M2 polarized macrophages has also been pointed out that Tumor cell-derived Wnt ligands induce M2-like polarization of TAM via traditional $\mathrm{Wnt} /$-catenin signaling, resulting in tumor migration, development, immunosuppression and metastasis in HCC(Yang et al., 2018a). We summarize the current relevant research progress in Table 8 . 
TABLE 7 | Tumor-promoting immune cells: cancer-associated fibroblasts.

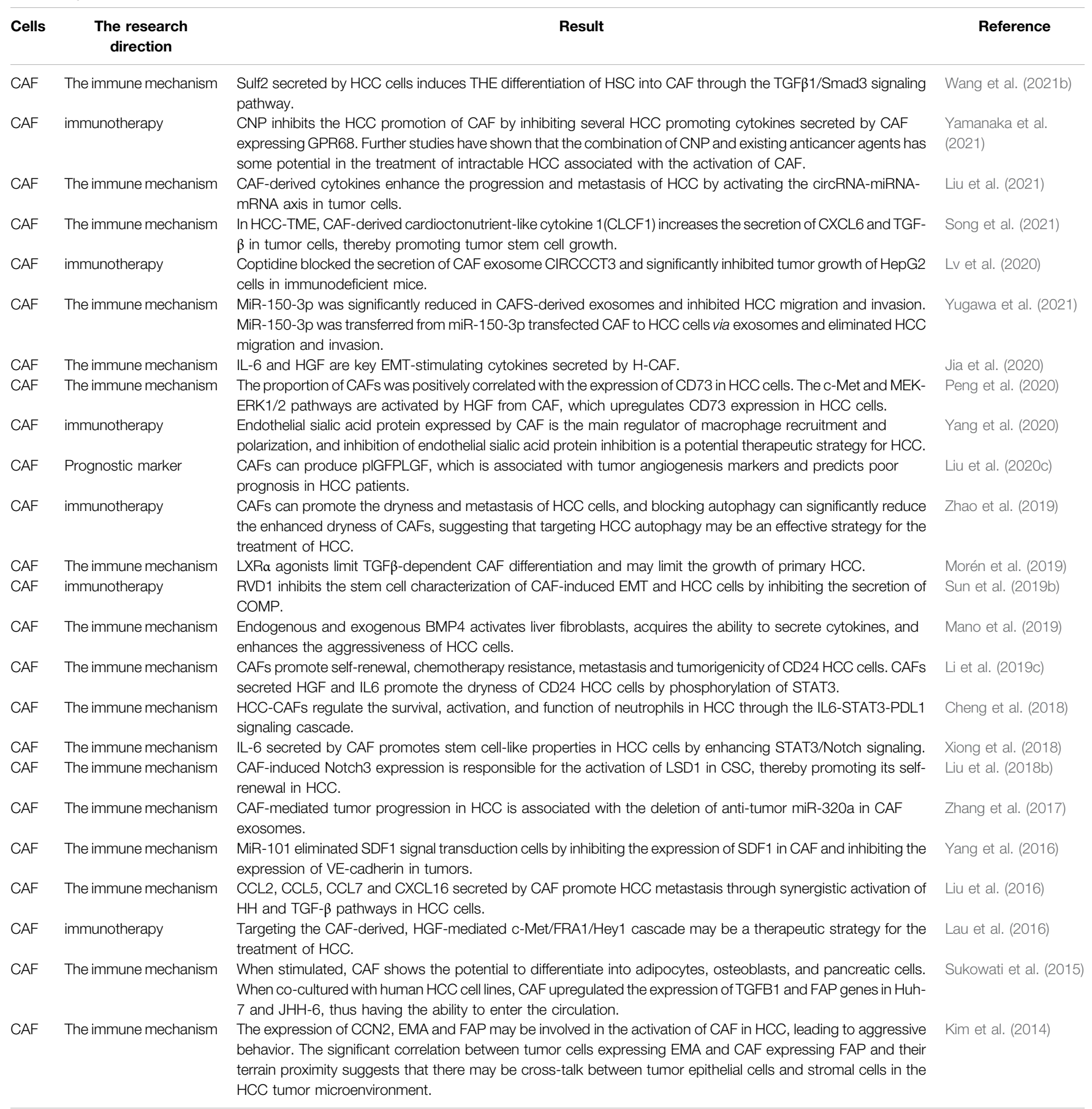

\section{THE CONTROVERSIAL IMMUNE CELL TYPE IN CANCER: B CELLS}

One type of immune cells that cannot be ignored in the HCC tumor microenvironment is B cells. According to the current relevant studies, it is not clear whether B cells are "good" or "bad". Some studies have reported that B cells promote HCC, while others have reported the opposite effect. B cells, on the one hand, release cytokines that comport with CTL activity and serve as potent antigen-presenting cells (APCs). On the other hand, they may be tumorigenic due to the production of cytokines that attract MDSC and promote angiogenesis (de Visser et al., 2005; Tsou et al., 2016). Studies have shown that CCL20 derived from tumor cells interacts with CD19CD5 B cells overexpressed by CCR6 to promote the development of HCC, possibly through enhanced angiogenesis (He et al., 2017). Liu et al. 's study 


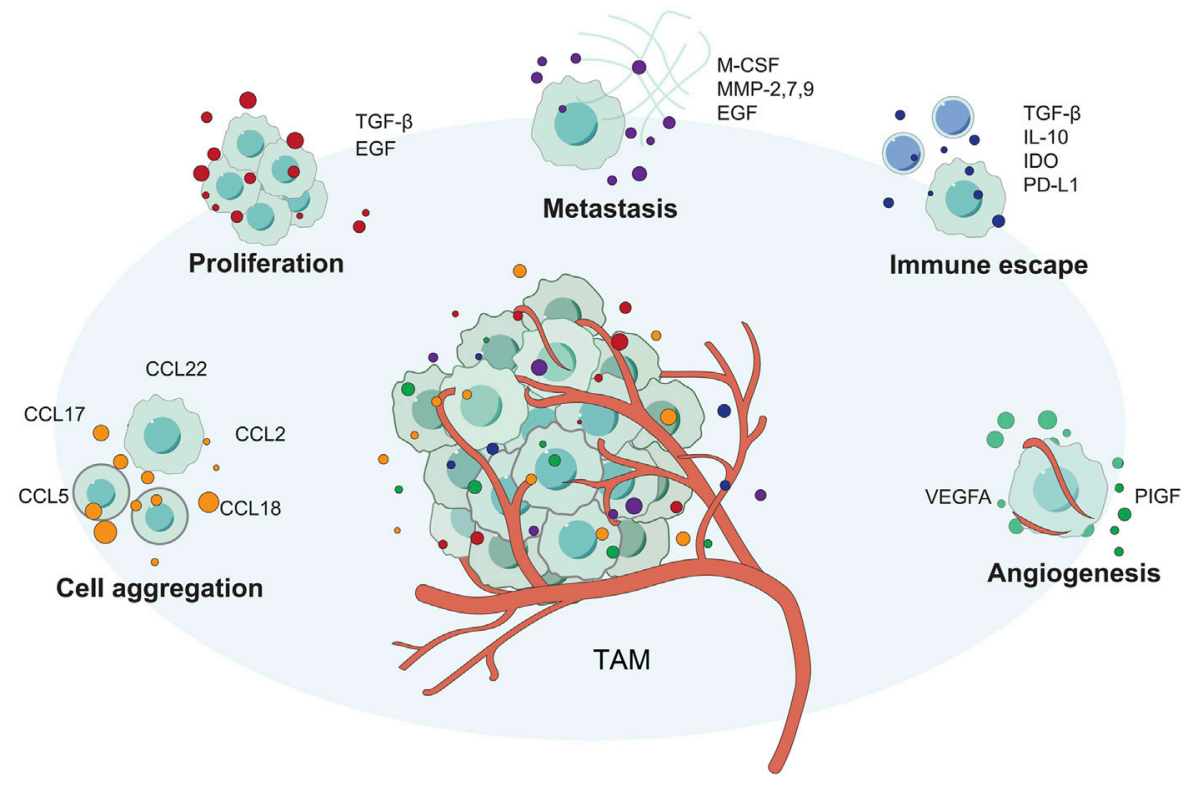

FIGURE 4 | The different ways that TAM supports tumor growth. TAM promotes tumor proliferation, invasion, angiogenesis, and immune escape through various methods.

TABLE 8 | Tumor-promoting immune cells: M2-polarized macrophages.

\begin{tabular}{|c|c|c|c|}
\hline Cells & $\begin{array}{l}\text { The research } \\
\text { direction }\end{array}$ & Result & Reference \\
\hline $\begin{array}{l}\text { M2-polarized } \\
\text { macrophages }\end{array}$ & $\begin{array}{l}\text { The immune } \\
\text { mechanism }\end{array}$ & $\begin{array}{l}\text { MicroRNA (miR-17-92) clusters from the extracellular vesicles (EVs) of M2-polarized tumor- } \\
\text { associated macrophages (M2-TAMs) stimulate the imbalance of the TGF- } \beta 1 / \text { BMP-7 pathway, } \\
\text { TGF- } \beta 1 / B M P-7 \text { pathway imbalance significantly promotes HCC cell invasion and stem cells by } \\
\text { increasing the expression of differentiation inhibitor } 1 \text { (ID1). }\end{array}$ & Ning et al. (2021) \\
\hline $\begin{array}{l}\text { M2-polarized } \\
\text { macrophages }\end{array}$ & $\begin{array}{l}\text { The immune } \\
\text { mechanism }\end{array}$ & $\begin{array}{l}\text { Elevated levels of Mir-15B are transferred from arsenite-treated THP-1 (AS-THP-1) cells to HCC } \\
\text { cells via Mir-15b in EVs, inhibit Hippo pathway activation by targeting LATS1, and participate in the } \\
\text { migration and invasion of proliferation-promoting HCC cells. }\end{array}$ & Li et al. (2021) \\
\hline $\begin{array}{l}\text { M2-polarized } \\
\text { macrophages }\end{array}$ & $\begin{array}{l}\text { The immune } \\
\text { mechanism }\end{array}$ & $\begin{array}{l}\beta 2-A R \text { promotes the occurrence and development of HCC by silencing GRK2 in M2 polarized } \\
\text { macrophages. }\end{array}$ & Wu et al. (2019b) \\
\hline $\begin{array}{l}\text { M2-polarized } \\
\text { macrophages }\end{array}$ & immunotherapy & $\begin{array}{l}\text { Tumor cell-derived Wnt ligands stimulate M2-like polarization of TAM through classical Wnt/ } \\
\beta \text {-catenin signaling, which leads to tumor growth, migration, metastasis, and immunosuppression } \\
\text { in HCC. }\end{array}$ & $\begin{array}{l}\text { Yang et al. } \\
\text { (2018a) }\end{array}$ \\
\hline $\begin{array}{l}\text { M2-polarized } \\
\text { macrophages }\end{array}$ & immunotherapy & $\begin{array}{l}\text { M2-polarized macrophages promote the migration and EMT of HCC cells through the TLR4/ } \\
\text { STAT3 signaling pathway, suggesting that TLR4 may be a new therapeutic target. }\end{array}$ & Yao et al. (2018) \\
\hline
\end{tabular}

confirmed that Selective recruitment of CXCR3 (+) B cells Bridges the pro-inflammatory interleukin-17 response and the polarization of tumorigenic macrophages in the tumor environment, and blocking the migration or function of CXCR3+ B cells may help to overcome HCC (Liu et al., 2015). Therefore, B cells are involved in both the development and inhibition of HCC. Table 9 highlights the most recent reliable research on the involvement of B cells in HCC.

\section{CONCLUSIONS AND PERSPECTIVES}

With the development of single-cell sequencing and other technologies, we have the opportunity to further explore TME.
Immunotherapy, a new tumor treatment method, also has a better and broader application prospect. However, at present, it is still too early for immunotherapy to replace traditional chemotherapeutic therapy, and there is still a long way to go in the process of clinical application. However, immunotherapy can be regarded as a good alternative therapy for patients with chemotherapy resistance. As mentioned in this paper, immunotherapies for tumor suppressor related immune cells, such as effect DCs, as well as tumor promoting immune cells, such as MDSC/Treg, are being developed one after another.

Compared with traditional chemotherapy, immunotherapy has many advantages. For example, immunotherapy has fewer overall side effects than chemotherapy and, once effective, may lead to long-term survival and even clinical cure. In addition, 
TABLE 9 | The controversial immune cell type in cancer: B cells.

\begin{tabular}{|c|c|c|c|}
\hline Cells & $\begin{array}{l}\text { The research } \\
\text { direction }\end{array}$ & Result & Reference \\
\hline B cells & Prognostic marker & $\begin{array}{l}\text { CD20 B cells, naive B cells, and CD27 isotypic transformed memory B cells are independent prognostic factors } \\
\text { for survival in HCC. During the progression of HCC, intratumoral infiltration of B cells is significantly impaired. High } \\
\text { density of tumor-infiltrating B cells means better clinical outcome. }\end{array}$ & Zhang et al. (2019) \\
\hline B cells & $\begin{array}{l}\text { The immune } \\
\text { mechanism }\end{array}$ & $\begin{array}{l}\text { In mice with } \mathrm{HCC}, \mathrm{B} \text { cell depletion blocked the production of these macrophages, increased anti-tumor T cell } \\
\text { response, and reduced } \mathrm{HCC} \text { growth. This pathway is involved in the increased expression of DNA } \\
\text { methyltransferase } 1 \text { and } \mathrm{EZH} 2 \text { in } \mathrm{HCC} \text { and } \mathrm{HCC} \text { cells. }\end{array}$ & Wei et al. (2019) \\
\hline B cells & Prognostic marker & $\begin{array}{l}\text { Tumor derived exosome-activated B cells strongly express Tim-1 protein and have inhibitory activity against CD8 } \\
\text { T cells. Exogenous HMGB1 activates B cells and promotes the expansion of Tim-1 Breg cells through Toll-like } \\
\text { receptor (TLR) } 2 / 4 \text { and mitogen-activated protein kinase (MAPK) signaling pathways. Accumulation of TIM- } \\
\text { 1BREG cells in tumors is associated with advanced disease, early recurrence, and reduced survival in HCC } \\
\text { patients. }\end{array}$ & Ye et al. (2018) \\
\hline B cells & $\begin{array}{l}\text { The immune } \\
\text { mechanism }\end{array}$ & $\begin{array}{l}\text { In MDR2 mice, CD20 B cell ablation promoted age-mediated fibrosis regression and inhibited the tumorigenic } \\
\text { TNF } \alpha / N F-\kappa B \text { pathway. }\end{array}$ & Faggioli et al. (2018) \\
\hline B cells & $\begin{array}{l}\text { The immune } \\
\text { mechanism }\end{array}$ & $\begin{array}{l}\text { B cells and IgG2 may play an important role in the inhibition of liver tumorigenesis. Hepatocellular specific } \\
\text { expression of ras oncogene may play a role in the inhibition of B cells, and B cells and T cells may be inhibited in } \\
\text { developing liver tumors. }\end{array}$ & Wang et al. (2017) \\
\hline B cells & $\begin{array}{l}\text { The immune } \\
\text { mechanism }\end{array}$ & $\begin{array}{l}\text { CCL20 derived from tumor cells interacts with CD19CD5 B cells overexpressed by CCR6 to promote the } \\
\text { development of HCC, possibly through enhanced angiogenesis. }\end{array}$ & He et al. (2017) \\
\hline B cells & Prognostic marker & $\begin{array}{l}\text { More than } 50 \% \text { of } \mathrm{B} \text { cells in } \mathrm{HCC} \text { exhibit } \mathrm{Fc} \gamma \mathrm{RII} \text {-activated phenotypes, and the production of Fc } \gamma \text { RII-activated } \\
\mathrm{B} \text { cells may represent a mechanism through which immune activation is associated with immune tolerance in the } \\
\text { tumor environment. }\end{array}$ & Ouyang et al. (2016) \\
\hline B cells & $\begin{array}{l}\text { The immune } \\
\text { mechanism }\end{array}$ & $\begin{array}{l}\text { A novel oncogenic PD-1(HI) B cell subtype has been identified in human HCC that exhibits a phenotype distinct } \\
\text { from that of surrounding regulatory B cells. TLR4-mediated upregulation of BCL6 is critical for inducing PD-1(HI) } \\
\text { B cells, which act through an IL10-dependent pathway after interacting with PD-L1, thereby causing T cell } \\
\text { dysfunction and promoting disease progression. }\end{array}$ & Xiao et al. (2016) \\
\hline B cells & Prognostic marker & $\begin{array}{l}\text { Tumor infiltrating T cells and B cells are in close contact with each other, and their density is associated with } \\
\text { superior survival in patients with HCC. }\end{array}$ & Garnelo et al. (2017) \\
\hline B cells & $\begin{array}{l}\text { The immune } \\
\text { mechanism }\end{array}$ & $\begin{array}{l}\text { Selective recruitment of CXCR3 (+) B cells Bridges the pro-inflammatory interleukin-17 response and the } \\
\text { polarization of tumorigenic macrophages in the tumor environment, and blocking the migration or function of } \\
\text { CXCR3 (+) B cells may contribute to the defeat of HCC. }\end{array}$ & Liu et al. (2015) \\
\hline B cells & $\begin{array}{l}\text { The immune } \\
\text { mechanism }\end{array}$ & $\begin{array}{l}\text { After liver MET transfection, TUNEL (+) hepatocytes were increased in B cell-or macrophage-deficient mice, } \\
\text { suggesting that these cells provide a protective effect against MET-induced hepatocyte apoptosis. }\end{array}$ & Subleski et al. (2015) \\
\hline B cells & $\begin{array}{l}\text { The immune } \\
\text { mechanism }\end{array}$ & $\begin{array}{l}\text { An increase in intrahepatic B cells at the edge of the tumor was positively associated with tumor invasion } \\
\text { characteristics and more tumor recurrence. Bregs directly interact with HCC cells through the CD40/CD154 } \\
\text { signaling pathway, thereby promoting the growth and aggressiveness of HCC. }\end{array}$ & Shao et al. (2014) \\
\hline B cells & $\begin{array}{l}\text { The immune } \\
\text { mechanism }\end{array}$ & $\begin{array}{l}\text { As a trans activator, } \mathrm{HBx} \text { can regulate the activated B nuclear factor kappa-light chain enhancer }(\mathrm{NF}-\kappa \mathrm{B}) \text { and } \\
\text { transcription factor } \mathrm{AP}-2 . \mathrm{HBx} \text { may cause the loss of apoptotic function, or directly contribute to carcinogenesis } \\
\text { by realizing the transformation function, and accelerate the development of HCC. }\end{array}$ & Zhang et al. (2014) \\
\hline B cells & $\begin{array}{l}\text { The immune } \\
\text { mechanism }\end{array}$ & $\begin{array}{l}\text { Activation-induced cytidine deaminase (AID) acts as genomic mutants in activated B cells, and inappropriate } \\
\text { expression of AID is associated with immunopathological phenotypes of human B cell malignancies. Abnormal } \\
\text { activation of AID in hepatocytes leads to the accumulation of multiple genetic changes in the p53 gene, which may } \\
\text { enhance genetic susceptibility to mutagenesis leading to HCC development. }\end{array}$ & Kou et al. (2007) \\
\hline
\end{tabular}

immunotherapy can be used as an important anti-tumor adjuvant therapy in addition to chemotherapy, radiotherapy and surgery. Appropriate immunotherapy can kill the tiny residual tumor cells after chemotherapy or some tumor cells resistant to chemotherapy. Immunotherapy should be considered for patients who are intolerant to chemotherapy or have extensive metastasis and cannot undergo surgery, radiotherapy or chemotherapy (Yang, 2015).

At present, the mainstream immunotherapy mainly includes CAR $\mathrm{T}$ therapy/immune checkpoint inhibitor therapy (PD-1, $\mathrm{PD}-\mathrm{L} 1$, etc.)/tumor vaccine. CAR- $\mathrm{T}$ is the $\mathrm{T}$ cells, biological engineering, when the cancer has an immune deficiency, immune surveillance, give play to the role of the case, through the biological engineering to determine the targets of leukemia, it specifically chimeric in T cells, to attack the leukemia cells, the effect is significant, but easy to appear "storm" cells, serious and even cause death (Feins et al., 2019). Immune checkpoint inhibitor therapy has the advantage of long-term survival and relatively small adverse reactions. This therapy activates tumorspecific immune cells in the body by removing or attenuating the negative regulatory factors of immunoreactive cells, but it is not suitable for all patients. The higher the mutation load, the better the treatment response. Therefore, biomarkers should be used to screen the dominant population. The most common predictive indicators of PD-1/PD-L1 immune checkpoint inhibitors are microsatellite instability, PD-L1 and tumor mutation load (Pinato et al., 2019). The treatment of cancer vaccines is still incomplete.

Immunotherapy is not the end of tumor therapy; on the contrary, tumor immunotherapy represented by immune checkpoints has just opened a new chapter in tumor therapy. Combined with the basic and characteristics of immunotherapy, 
with the deepening of human understanding of tumors, tumors as a chronic disease that can be cured are no longer so far out of reach.

\section{AUTHOR CONTRIBUTIONS}

The manuscript had three first authors who made equal contributions to the project. XH, GS, and YZ were responsible for collecting information and design reviews of relevant studies. XK and DR are responsible for drawing the pictures. In addition, we have three corresponding authors in this manuscript. WT, JS, and XW contributed to the interpretation, editing and critical revision of the manuscript.

\section{REFERENCES}

Ali, M. Y., Grimm, C. F., Ritter, M., Mohr, L., Allgaier, H.-P., Weth, R., et al. (2005). Activation of Dendritic Cells by Local Ablation of Hepatocellular Carcinoma. J. Hepatol. 43, 817-822. doi:10.1016/j.jhep.2005.04.016

Anson, M., Crain-Denoyelle, A.-M., Baud, V., Chereau, F., Gougelet, A., Terris, B., et al. (2012). Oncogenic $\beta$-catenin Triggers an Inflammatory Response that Determines the Aggressiveness of Hepatocellular Carcinoma in Mice. J. Clin. Invest. 122, 586-599. doi:10.1172/jci43937

Aras, S., and Zaidi, M. R. (2017). TAMeless Traitors: Macrophages in Cancer Progression and Metastasis. Br. J. Cancer 117, 1583-1591. doi:10.1038/ bjc. 2017.356

Arihara, F., Mizukoshi, E., Kitahara, M., Takata, Y., Arai, K., Yamashita, T., et al. (2013). Increase in CD14+HLA-DR-/low Myeloid-Derived Suppressor Cells in Hepatocellular Carcinoma Patients and its Impact on Prognosis. Cancer Immunol. Immunother. 62, 1421-1430. doi:10.1007/s00262-013-1447-1

Asafo-Agyei, K. O., and Samant, H. (2021). HCC. Treasure Island(FL): StatPearls.

Barajas, M., Mazzolini, G., Genove, G., Bilbao, R., Narvaiza, I., Schmitz, V., et al. (2001). Gene Therapy of Orthotopic Hepatocellular Carcinoma in Rats Using Adenovirus Coding for Interleukin 12. Hepatology 33, 52-61. doi:10.1053/ jhep.2001.20796

Bennett, S. R. M., Carbone, F. R., Karamalis, F., Flavell, R. A., Miller, J. F. A. P., and Heath, W. R. (1998). Help for Cytotoxic-T-Cell Responses Is Mediated by CD40 Signalling. Nature 393, 478-480. doi:10.1038/30996

Bennett, S. R. M., Carbone, F. R., Karamalis, F., Miller, J. F. A. P., and Heath, W. R. (1997). Induction of a CD8+ Cytotoxic T Lymphocyte Response by CrossPriming Requires Cognate CD4+ T Cell Help. J. Exp. Med. 186, 65-70. doi:10.1084/jem.186.1.65

Berod, L., Puttur, F., Huehn, J., and Sparwasser, T. (2012). Tregs in Infection and Vaccinology: Heroes or Traitors? Microb. Biotechnol. 5, 260-269. doi:10.1111/ j.1751-7915.2011.00299.x

Borst, J., Ahrends, T., Bąbała, N., Melief, C. J. M., and Kastenmüller, W. (2018). CD4+ T Cell Help in Cancer Immunology and Immunotherapy. Nat. Rev. Immunol. 18, 635-647. doi:10.1038/s41577-018-0044-0

Bourgeois, C., Rocha, B., and Tanchot, C. (2002). A Role for CD40 Expression on CD8+ T Cells in the Generation of CD8+ T Cell Memory. Science 297, 2060-2063. doi:10.1126/science.1072615

Brown, Z. J., Fu, Q., Ma, C., Kruhlak, M., Zhang, H., Luo, J., et al. (2018). Carnitine Palmitoyltransferase Gene Upregulation by Linoleic Acid Induces CD4+ T Cell Apoptosis Promoting HCC Development. Cell Death Dis 9, 620. doi:10.1038/ s41419-018-0687-6

Cabrera, R., Ararat, M., Xu, Y., Brusko, T., Wasserfall, C., Atkinson, M. A., et al. (2013). Immune Modulation of Effector CD4+ and Regulatory T Cell Function by Sorafenib in Patients with Hepatocellular Carcinoma. Cancer Immunol. Immunother. 62, 737-746. doi:10.1007/s00262-012-1380-8

Cai, M.-Y., Xu, Y.-F., Qiu, S.-J., Ju, M.-J., Gao, Q., Li, Y.-W., et al. (2009). Human Leukocyte Antigen-G Protein Expression Is an Unfavorable Prognostic

\section{FUNDING}

We are grateful for the grants from the National Natural Science Key Foundation of China (Grant No. 31930020) and National Natural Science Foundation of China (Grant No. 81771716).

\section{ACKNOWLEDGMENTS}

We would like to express our sincere thanks to Magdalens Klink, the author of the book "Interaction of immune and cancer cells." Our pictures have been partially changed and repainted on the basis of this book. At the same time, this book has also given us a lot of writing inspiration.

Predictor of Hepatocellular Carcinoma Following Curative Resection. Clin. Cancer Res. 15, 4686-4693. doi:10.1158/1078-0432.ccr-09-0463

Cao, M., Huang, W., Chen, Y., Li, G., Liu, N., Wu, Y., et al. (2021). Chronic Restraint Stress Promotes the Mobilization and Recruitment of MyeloidDerived Suppressor Cells through Beta-Adrenergic-Activated CXCL5CXCR2-Erk Signaling Cascades. Int. J. Cancer 1, 1.

Carr, B. I., and Metes, D. M. (2012). Peripheral Blood Lymphocyte Depletion after Hepatic Arterial 90Yttrium Microsphere Therapy for Hepatocellular Carcinoma. Int. J. Radiat. Oncolog $y^{*}$ Biolog $y^{*}$ Physics $\quad 82, \quad 1179-1184$. doi:10.1016/j.ijrobp.2010.10.042

Chang, C.-C., Dinh, T. K., Lee, Y.-A., Wang, F.-N., Sung, Y.-C., Yu, P.-L., et al. (2020). Nanoparticle Delivery of $\mathrm{MnO} 2$ and Antiangiogenic Therapy to Overcome Hypoxia-Driven Tumor Escape and Suppress Hepatocellular Carcinoma. ACS Appl. Mater. Inter. 12, 44407-44419. doi:10.1021/ acsami.0c08473

Chang, C.-J., Yang, Y.-H., Chiu, C.-J., Lu, L.-C., Liao, C.-C., Liang, C.-W., et al. (2018). Targeting Tumor-Infiltrating Ly6G+ Myeloid Cells Improves Sorafenib Efficacy in Mouse Orthotopic Hepatocellular Carcinoma. Int. J. Cancer 142, 1878-1889. doi:10.1002/ijc.31216

Chaoul, N., Mancarella, S., Lupo, L., Giannelli, G., and Dituri, F. (2020). Impaired Anti-tumor T Cell Response in Hepatocellular Carcinoma. Cancers (Basel) 12, 1. doi:10.3390/cancers 12030627

Chen, K., Wu, Z., Zhao, H., Wang, Y., Ge, Y., Wang, D., et al. (2020). XCL1/ Glypican-3 Fusion Gene Immunization Generates Potent Antitumor Cellular Immunity and Enhances Anti-PD-1 Efficacy. Cancer Immunol. Res. 8, 81-93. doi:10.1158/2326-6066.cir-19-0210

Chen, L., Zhou, S., Qin, J., Hu, H., Ma, H., Liu, B., et al. (2013). Combination of SLC Administration and Tregs Depletion Is an Attractive Strategy for Targeting Hepatocellular Carcinoma. Mol. Cancer 12, 153. doi:10.1186/1476-4598-12-153

Chen, M.-L., Yan, B.-S., Lu, W.-C., Chen, M.-H., Yu, S.-L., Yang, P.-C., et al. (2014). Sorafenib Relieves Cell-Intrinsic and Cell-Extrinsic Inhibitions of Effector $\mathrm{T}$ Cells in Tumor Microenvironment to Augment Antitumor Immunity. Int. J. Cancer 134, 319-331. doi:10.1002/ijc.28362

Chen, Y., Hao, X., Sun, R., Wei, H., and Tian, Z. (2019). Natural Killer Cell-Derived Interferon-Gamma Promotes Hepatocellular Carcinoma through the Epithelial Cell Adhesion Molecule-Epithelial-to-Mesenchymal Transition Axis in Hepatitis B Virus Transgenic Mice. Hepatology 69, 1735-1750. doi:10.1002/ hep. 30317

Chen, Y., Yang, D., Li, S., Gao, Y., Jiang, R., Deng, L., et al. (2012). Development of a Listeria Monocytogenes-Based Vaccine against Hepatocellular Carcinoma. Oncogene 31, 2140-2152. doi:10.1038/onc.2011.395

Cheng, L., Du, X., Wang, Z., Ju, J., Jia, M., Huang, Q., et al. (2014). Hyper-IL-15 Suppresses Metastatic and Autochthonous Liver Cancer by Promoting Tumour-specific CD8+ T Cell Responses. J. Hepatol. 61, 1297-1303. doi:10.1016/j.jhep.2014.07.004

Cheng, L. E., Ohlen, C., Nelson, B. H., and Greenberg, P. D. (2002). Enhanced Signaling through the IL-2 Receptor in CD8+ T Cells Regulated by Antigen Recognition Results in Preferential Proliferation and Expansion of Responding 
CD8+ T Cells rather Than Promotion of Cell Death. Proc. Natl. Acad. Sci. 99, 3001-3006. doi:10.1073/pnas.052676899

Cheng, Y., Li, H., Deng, Y., Tai, Y., Zeng, K., Zhang, Y., et al. (2018). Cancerassociated Fibroblasts Induce PDL1+ Neutrophils through the IL6-STAT3 Pathway that foster Immune Suppression in Hepatocellular Carcinoma. Cell Death Dis 9, 422. doi:10.1038/s41419-018-0458-4

Chew, V., Tow, C., Teo, M., Wong, H. L., Chan, J., Gehring, A., et al. (2010). Inflammatory Tumour Microenvironment Is Associated with superior Survival in Hepatocellular Carcinoma Patients. J. Hepatol. 52, 370-379. doi:10.1016/ j.jhep.2009.07.013

Chiu, D. K.-C., Tse, A. P.-W., Xu, I. M.-J., Di Cui, J., Lai, R. K.-H., Li, L. L., et al. (2017). Hypoxia Inducible Factor HIF-1 Promotes Myeloid-Derived Suppressor Cells Accumulation through ENTPD2/CD39L1 in Hepatocellular Carcinoma. Nat. Commun. 8, 517. doi:10.1038/s41467-017-00530-7

Chiu, D. K.-C., Yuen, V. W.-H., Cheu, J. W.-S., Wei, L. L., Ting, V., Fehlings, M., et al. (2020). Hepatocellular Carcinoma Cells Up-Regulate PVRL1, Stabilizing PVR and Inhibiting the Cytotoxic T-Cell Response via TIGIT to Mediate Tumor Resistance to PD1 Inhibitors in Mice. Gastroenterology 159, 609-623. doi:10.1053/j.gastro.2020.03.074

Cicinnati, V. R., Zhang, X., Yu, Z., Ferencik, S., Schmitz, K. J., Dworacki, G., et al. (2006). Increased Frequencies of CD8+ T Lymphocytes Recognizing Wild-type P53-Derived Epitopes in Peripheral Blood Correlate with Presence of Epitope Loss Tumor Variants in Patients with Hepatocellular Carcinoma. Int. J. Cancer 119, 2851-2860. doi:10.1002/ijc.22251

de Visser, K. E., Korets, L. V., and Coussens, L. M. (2005). De Novo carcinogenesis Promoted by Chronic Inflammation Is B Lymphocyte Dependent. Cancer Cell 7, 411-423. doi:10.1016/j.ccr.2005.04.014

Deng, Y., Cheng, J., Fu, B., Liu, W., Chen, G., Zhang, Q., et al. (2017). Hepatic Carcinoma-Associated Fibroblasts Enhance Immune Suppression by Facilitating the Generation of Myeloid-Derived Suppressor Cells. Oncogene 36, 1090-1101. doi:10.1038/onc.2016.273

Dhanasekaran, R., Park, J., Yevtodiyenko, A., Bellovin, D. I., Adam, S. J., Kd, A. R., et al. (2020). MYC ASO Impedes Tumorigenesis and Elicits Oncogene Addiction in Autochthonous Transgenic Mouse Models of HCC and RCC. Mol. Ther. - Nucleic Acids 21, 850-859. doi:10.1016/j.omtn.2020.07.008

Duffy, A. G., Ulahannan, S. V., Makorova-Rusher, O., Rahma, O., Wedemeyer, H., Pratt, D., et al. (2017). Tremelimumab in Combination with Ablation in Patients with Advanced Hepatocellular Carcinoma. J. Hepatol. 66, 545-551. doi:10.1016/j.jhep.2016.10.029

Eggert, T., Wolter, K., Ji, J., Ma, C., Yevsa, T., Klotz, S., et al. (2016). Distinct Functions of Senescence-Associated Immune Responses in Liver Tumor Surveillance and Tumor Progression. Cancer Cell 30, 533-547. doi:10.1016/ j.ccell.2016.09.003

Elinav, E., Abd-Elnabi, A., Pappo, O., Bernstein, I., Klein, A., Engelhardt, D., et al. (2006). Suppression of Hepatocellular Carcinoma Growth in Mice via Leptin, Is Associated with Inhibition of Tumor Cell Growth and Natural Killer Cell Activation. J. Hepatol. 44, 529-536. doi:10.1016/ j.jhep.2005.08.013

Evdokimova, V. N., Liu, Y., Potter, D. M., and Butterfield, L. H. (2007). AFPspecific CD4+ Helper T-Cell Responses in Healthy Donors and HCC Patients. J. Immunother. 30, 425-437. doi:10.1097/cji.0b013e31802fd8e2

Faggioli, F., Palagano, E., Di Tommaso, L., Donadon, M., Marrella, V., Recordati, C., et al. (2018). B Lymphocytes Limit Senescence-Driven Fibrosis Resolution and Favor Hepatocarcinogenesis in Mouse Liver Injury. Hepatology 67, 1970-1985. doi:10.1002/hep.29636

Fan, Y., Gao, Y., Rao, J., Wang, K., Zhang, F., and Zhang, C. (2017). YAP-1 Promotes Tregs Differentiation in Hepatocellular Carcinoma by Enhancing TGFBR2 Transcription. Cell Physiol Biochem 41, 1189-1198. doi:10.1159/000464380

Farhood, B., Najafi, M., and Mortezaee, K. (2019). CD8 + Cytotoxic T Lymphocytes in Cancer Immunotherapy: A Review. J. Cell Physiol 234, 8509-8521. doi: $10.1002 /$ jcp. 27782

Feins, S., Kong, W., Williams, E. F., Milone, M. C., and Fraietta, J. A. (2019). An Introduction to Chimeric Antigen Receptor (CAR) T-cell Immunotherapy for Human Cancer. Am. J. Hematol. 94, S3-S9. doi:10.1002/ajh.25418

Ferlay, J., Soerjomataram, I., Dikshit, R., Eser, S., Mathers, C., Rebelo, M., et al. (2015). Cancer Incidence and Mortality Worldwide: Sources, Methods and Major Patterns in GLOBOCAN 2012. Int. J. Cancer 136, E359-E386. doi:10.1002/ijc.29210
Fu, J., Xu, D., Liu, Z., Shi, M., Zhao, P., Fu, B., et al. (2007). Increased Regulatory T Cells Correlate with CD8 T-Cell Impairment and Poor Survival in Hepatocellular Carcinoma Patients. Gastroenterology 132, 2328-2339. doi:10.1053/ j.gastro.2007.03.102

Gabrielson, A., Wu, Y., Wang, H., Jiang, J., Kallakury, B., Gatalica, Z., et al. (2016). Intratumoral CD3 and CD8 T-Cell Densities Associated with Relapse-free Survival in HCC. Cancer Immunol. Res. 4, 419-430. doi:10.1158/2326-6066.cir15-0110

Gabrilovich, D. I., Bronte, V., Chen, S.-H., Colombo, M. P., Ochoa, A., OstrandRosenberg, S., et al. (2007). The Terminology Issue for Myeloid-Derived Suppressor Cells. Cancer Res. 67, 425. doi:10.1158/0008-5472.can-06-3037

Gabrilovich, D. I. (2017). Myeloid-Derived Suppressor Cells. Cancer Immunol. Res. 5, 3-8. doi:10.1158/2326-6066.cir-16-0297

Gabrilovich, D. I., Ostrand-Rosenberg, S., and Bronte, V. (2012). Coordinated Regulation of Myeloid Cells by Tumours. Nat. Rev. Immunol. 12, 253-268. doi:10.1038/nri3175

Gao, Q., Qiu, S.-J., Fan, J., Zhou, J., Wang, X.-Y., Xiao, Y.-S., et al. (2007). Intratumoral Balance of Regulatory and Cytotoxic T Cells Is Associated with Prognosis of Hepatocellular Carcinoma after Resection. Jco 25, 2586-2593. doi:10.1200/jco.2006.09.4565

Garnelo, M., Tan, A., Her, Z., Yeong, J., Lim, C. J., Chen, J., et al. (2017). Interaction between Tumour-Infiltrating B Cells and T Cells Controls the Progression of Hepatocellular Carcinoma. Gut 66, 342-351. doi:10.1136/ gutjnl-2015-310814

Goyal, L., Zheng, H., Abrams, T. A., Miksad, R., Bullock, A. J., Allen, J. N., et al. (2019). A Phase II and Biomarker Study of Sorafenib Combined with Modified FOLFOX in Patients with Advanced Hepatocellular Carcinoma. Clin. Cancer Res. 25, 80-89. doi:10.1158/1078-0432.ccr-18-0847

Guillerey, C., Huntington, N. D., and Smyth, M. J. (2016). Targeting Natural Killer Cells in Cancer Immunotherapy. Nat. Immunol. 17, 1025-1036. doi:10.1038/ ni.3518

Habif, G., Crinier, A., André, P., Vivier, E., and Narni-Mancinelli, E. (2019). Targeting Natural Killer Cells in Solid Tumors. Cell Mol Immunol 16, 415-422. doi:10.1038/s41423-019-0224-2

Hage, C., Hoves, S., Strauss, L., Bissinger, S., Prinz, Y., Pöschinger, T., et al. (2019). Sorafenib Induces Pyroptosis in Macrophages and Triggers Natural Killer CellMediated Cytotoxicity against Hepatocellular Carcinoma. Hepatology 70, 1280-1297. doi:10.1002/hep.30666

Han, Q., Wang, Y., Pang, M., and Zhang, J. (2017). STAT3-blocked Whole-Cell Hepatoma Vaccine Induces Cellular and Humoral Immune Response against HCC. J. Exp. Clin. Cancer Res. 36, 156. doi:10.1186/s13046-017-0623-0

Hanahan, D., and Weinberg, R. A. (2011). Hallmarks of Cancer: the Next Generation. Cell 144, 646-674. doi:10.1016/j.cell.2011.02.013

Hanahan, D., and Weinberg, R. A. (2000). The Hallmarks of Cancer. Cell 100, 57-70. doi:10.1016/s0092-8674(00)81683-9

Hao, N. B., Lü, M. H., Fan, Y. H., Cao, Y. L., Zhang, Z. R., and Yang, S. M. (2012). Macrophages in Tumor Microenvironments and the Progression of Tumors. Clin. Dev. Immunol. 2012, 948098. doi:10.1155/2012/948098

He, H., Wu, J., Zang, M., Wang, W., Chang, X., Chen, X., et al. (2017). CCR6+ B Lymphocytes Responding to Tumor Cell-Derived CCL20 Support Hepatocellular Carcinoma Progression via Enhancing Angiogenesis. Am. J. Cancer Res. 7, 1151-1163.

Hiroishi, K., Eguchi, J., Baba, T., Shimazaki, T., Ishii, S., Hiraide, A., et al. (2010). Strong CD8+ T-Cell Responses against Tumor-Associated Antigens Prolong the Recurrence-free Interval after Tumor Treatment in Patients with Hepatocellular Carcinoma. J. Gastroenterol. 45, 451-458. doi:10.1007/ s00535-009-0155-2

Hoechst, B., Ormandy, L. A., Ballmaier, M., Lehner, F., Krüger, C., Manns, M. P., et al. (2008). A New Population of Myeloid-Derived Suppressor Cells in Hepatocellular Carcinoma Patients Induces CD4+CD25+Foxp3+ T Cells. Gastroenterology 135, 234-243. doi:10.1053/j.gastro.2008.03.020

Hoechst, B., Voigtlaender, T., Ormandy, L., Gamrekelashvili, J., Zhao, F., Wedemeyer, H., et al. (2009). Myeloid Derived Suppressor Cells Inhibit Natural Killer Cells in Patients with Hepatocellular Carcinoma via the NKp30 Receptor. Hepatology 50, 799-807. doi:10.1002/hep.23054

Homma, S., Komita, H., Sagawa, Y., Ohno, T., and Toda, G. (2005). Antitumour Activity Mediated by CD4+ Cytotoxic T Lymphocytes against MHC Class IINegative Mouse Hepatocellular Carcinoma Induced by Dendritic Cell Vaccine 
and Interleukin-12. Immunology 115, 451-461. doi:10.1111/j.13652567.2005.02179.x

Hu, Z., Chen, J., Zhou, S., Yang, N., Duan, S., Zhang, Z., et al. (2017). Mouse IP-10 Gene Delivered by Folate-Modified Chitosan Nanoparticles and Dendritic/ tumor Cells Fusion Vaccine Effectively Inhibit the Growth of Hepatocellular Carcinoma in Mice. Theranostics 7, 1942-1952. doi:10.7150/thno.16236

Huang, F., Chen, J., Lan, R., Wang, Z., Chen, R., Lin, J., et al. (2018). $\delta$-Catenin Peptide Vaccines Repress Hepatocellular Carcinoma Growth via CD8+ T Cell Activation. Oncoimmunology 7, e1450713. doi:10.1080/2162402x.2018.1450713

Irie, M., Homma, S., Komita, H., Zeniya, M., Kufe, D., Ohno, T., et al. (2004). Inhibition of Spontaneous Development of Liver Tumors by Inoculation with Dendritic Cells Loaded with Hepatocellular Carcinoma Cells in C3H/HeNCRJ Mice. Int. J. Cancer 111, 238-245. doi:10.1002/ijc.20247

Ishiyama, K., Ohdan, H., Ohira, M., Mitsuta, H., Arihiro, K., and Asahara, T. (2006). Difference in Cytotoxicity against Hepatocellular Carcinoma between Liver and Periphery Natural Killer Cells in Humans. Hepatology 43, 362-372. doi:10.1002/hep.21035

Iwai, Y., Ishida, M., Tanaka, Y., Okazaki, T., Honjo, T., and Minato, N. (2002). Involvement of PD-L1 on Tumor Cells in the Escape from Host Immune System and Tumor Immunotherapy by PD-L1 Blockade. Proc. Natl. Acad. Sci. 99, 12293-12297. doi:10.1073/pnas.192461099

Jia, C., Wang, G., Wang, T., Fu, B., Zhang, Y., Huang, L., et al. (2020). Cancerassociated Fibroblasts Induce Epithelial-Mesenchymal Transition via the Transglutaminase 2-dependent IL-6/IL6R/STAT3 axis in Hepatocellular Carcinoma. Int. J. Biol. Sci. 16, 2542-2558. doi:10.7150/ijbs.45446

Jiang, J., Ye, F., Yang, X., Zong, C., Gao, L., Yang, Y., et al. (2017). Peri-tumor Associated Fibroblasts Promote Intrahepatic Metastasis of Hepatocellular Carcinoma by Recruiting Cancer Stem Cells. Cancer Lett. 404, 19-28. doi:10.1016/j.canlet.2017.07.006

Jiang, R., Tang, J., Chen, Y., Deng, L., Ji, J., Xie, Y., et al. (2017). The Long Noncoding RNA Lnc-EGFR Stimulates T-Regulatory Cells Differentiation Thus Promoting Hepatocellular Carcinoma Immune Evasion. Nat. Commun. 8, 15129. doi:10.1038/ncomms15129

Jiang, W., Lu, Z., He, Y., and Diasio, R. B. (1997). Dihydropyrimidine Dehydrogenase Activity in Hepatocellular Carcinoma: Implication in 5Fluorouracil-Based Chemotherapy. Clin. Cancer Res. 3, 395-399.

Jinushi, M., Takehara, T., Tatsumi, T., Hiramatsu, N., Sakamori, R., Yamaguchi, S., et al. (2005). Impairment of Natural Killer Cell and Dendritic Cell Functions by the Soluble Form of MHC Class I-Related Chain A in Advanced Human Hepatocellular Carcinomas. J. Hepatol. 43, 1013-1020. doi:10.1016/j.jhep.2005.05.026

Kakita, N., Kanto, T., Itose, I., Kuroda, S., Inoue, M., Matsubara, T., et al. (2012). Comparative Analyses of Regulatory $\mathrm{T}$ Cell Subsets in Patients with Hepatocellular Carcinoma: A Crucial Role of CD25-FOXP3-T Cells. Int. J. Cancer 131, 2573-2583. doi:10.1002/ijc.27535

Kakumu, S., Ito, S., Ishikawa, T., Mita, Y., Tagaya, T., Fukuzawa, Y., et al. (2000). Decreased Function of Peripheral Blood Dendritic Cells in Patients with Hepatocellular Carcinoma with Hepatitis B and C Virus Infection. J. Gastroenterol. Hepatol. 15, 431-436. doi:10.1046/j.1440-1746.2000.02161.x

Kalathil, S. G., Hutson, A., Barbi, J., Iyer, R., and Thanavala, Y. (2019). Augmentation of IFN- $\Gamma+\mathrm{CD} 8+\mathrm{T}$ Cell Responses Correlates with Survival of HCC Patients on Sorafenib Therapy. JCI Insight 4. doi:10.1172/ jci.insight. 130116

Kalathil, S. G., Lugade, A. A., Miller, A., Iyer, R., and Thanavala, Y. (2016). PD-1+ and Foxp3+ T Cell Reduction Correlates with Survival of HCC Patients after Sorafenib Therapy. JCI Insight 1. doi:10.1172/jci.insight.86182

Kalathil, S. G., Wang, K., Hutson, A., Iyer, R., and Thanavala, Y. (2020). Tivozanib Mediated Inhibition of C-Kit/SCF Signaling on Tregs and MDSCs and Reversal of Tumor Induced Immune Suppression Correlates with Survival of HCC Patients. Oncoimmunology 9, 1824863. doi:10.1080/2162402x.2020.1824863

Kalluri, R. (2016). The Biology and Function of Fibroblasts in Cancer. Nat. Rev. Cancer 16, 582-598. doi:10.1038/nrc.2016.73

Kato, A., Miyazaki, M., Ambiru, S., Yoshitomi, H., Ito, H., Nakagawa, K., et al. (2001). Multidrug Resistance Gene (MDR-1) Expression as a Useful Prognostic Factor in Patients with Human Hepatocellular Carcinoma after Surgical Resection. J. Surg. Oncol. 78, 110-115. doi:10.1002/jso.1129

Kim, G. J., Rhee, H., Yoo, J. E., Ko, J. E., Lee, J. S., Kim, H., et al. (2014). Increased Expression of CCN2, Epithelial Membrane Antigen, and Fibroblast Activation Protein in Hepatocellular Carcinoma with
Fibrous Stroma Showing Aggressive Behavior. PLoS One 9, e105094. doi:10.1371/journal.pone.0105094

Kohga, K., Takehara, T., Tatsumi, T., Ishida, H., Miyagi, T., Hosui, A., et al. (2010). Sorafenib Inhibits the Shedding of Major Histocompatibility Complex Class I-Related Chain A on Hepatocellular Carcinoma Cells by Down-Regulating a Disintegrin and Metalloproteinase 9. Hepatology 51, 1264-1273. doi:10.1002/ hep. 23456

Kohga, K., Tatsumi, T., Takehara, T., Tsunematsu, H., Shimizu, S., Yamamoto, M., et al. (2010). Expression of CD133 Confers Malignant Potential by Regulating Metalloproteinases in Human Hepatocellular Carcinoma. J. Hepatol. 52, 872-879. doi:10.1016/j.jhep.2009.12.030

Kou, T., Marusawa, H., Kinoshita, K., Endo, Y., Okazaki, I.-m., Ueda, Y., et al. (2007). Expression of Activation-Induced Cytidine Deaminase in Human Hepatocytes during Hepatocarcinogenesis. Int. J. Cancer 120, 469-476. doi:10.1002/ijc.22292

Langhans, B., Nischalke, H. D., Krämer, B., Dold, L., Lutz, P., Mohr, R., et al. (2019). Role of Regulatory $\mathrm{T}$ Cells and Checkpoint Inhibition in Hepatocellular Carcinoma. Cancer Immunol. Immunother. 68, 2055-2066. doi:10.1007/ s00262-019-02427-4

Lau, E. Y. T., Lo, J., Cheng, B. Y. L., Ma, M. K. F., Lee, J. M. F., Ng, J. K. Y., et al. (2016). Cancer-Associated Fibroblasts Regulate Tumor-Initiating Cell Plasticity in Hepatocellular Carcinoma through C-Met/FRA1/HEY1 Signaling. Cell Rep. 15, 1175-1189. doi:10.1016/j.celrep.2016.04.019

Li, B., He, X., Pang, X., Zhang, H., Chen, J., and Chen, W. (2004). Elicitation of Both CD4+ and CD8+ T-Cell-Mediated Specific Immune Responses to HCA587 Protein by Autologous Dendritic Cells. Scand. J. Immunol. 60, 506-513. doi:10.1111/j.0300-9475.2004.01503.x

Li, C., Song, B., Santos, P. M., and Butterfield, L. H. (2019). Hepatocellular CancerDerived Alpha Fetoprotein Uptake Reduces CD1 Molecules on MonocyteDerived Dendritic Cells. Cell Immunol. 335, 59-67. doi:10.1016/ j.cellimm.2018.10.011

Li, C. X., Ling, C. C., Shao, Y., Xu, A., Li, X. C., Ng, K. T.-P., et al. (2016). CXCL10/ CXCR3 Signaling Mobilized-Regulatory T Cells Promote Liver Tumor Recurrence after Transplantation. J. Hepatol. 65, 944-952. doi:10.1016/ j.jhep.2016.05.032

Li, G., Liu, D., Cooper, T. K., Kimchi, E. T., Qi, X., Avella, D. M., et al. (2017). Successful Chemoimmunotherapy against Hepatocellular Cancer in a Novel Murine Model. J. Hepatol. 66, 75-85. doi:10.1016/j.jhep.2016.07.044

Li, J., Xue, J., Ling, M., Sun, J., Xiao, T., Dai, X., et al. (2021). MicroRNA-15b in Extracellular Vesicles from Arsenite-Treated Macrophages Promotes the Progression of Hepatocellular Carcinomas by Blocking the LATS1-Mediated Hippo Pathway. Cancer Lett. 497, 137-153. doi:10.1016/j.canlet.2020.10.023

Li, Y. M., Liu, Z. Y., Wang, J. C., Yu, J. M., Li, Z. C., Yang, H. J., et al. (2019). Receptor-Interacting Protein Kinase 3 Deficiency Recruits Myeloid-Derived Suppressor Cells to Hepatocellular Carcinoma through the Chemokine (C-X-C Motif) Ligand 1-Chemokine (C-X-C Motif) Receptor 2 Axis. Hepatology 70, 1564-1581. doi:10.1002/hep.30676

Li, Y., Wang, R., Xiong, S., Wang, X., Zhao, Z., Bai, S., et al. (2019). Cancerassociated Fibroblasts Promote the Stemness of CD24+ Liver Cells via Paracrine Signaling. J. Mol. Med. 97, 243-255. doi:10.1007/s00109-018-1731-9

Liang, C.-m., Ye, S.-1., Zhong, C.-p., Zheng, N., Bian, W., Sun, R.-x., et al. (2007). More Than Chemotaxis: a New Anti-tumor DC Vaccine Modified by rAAV2SLC. Mol. Immunol. 44, 3797-3804. doi:10.1016/j.molimm.2007.03.026

Liao, R., Sun, J., Wu, H., Yi, Y., Wang, J.-X., He, H.-W., et al. (2013). High Expression of IL-17 and IL-17RE Associate with Poor Prognosis of Hepatocellular Carcinoma. J. Exp. Clin. Cancer Res. 32, 3. doi:10.1186/1756-9966-32-3

Lim, C. J., Lee, Y. H., Pan, L., Lai, L., Chua, C., Wasser, M., et al. (2019). Multidimensional Analyses Reveal Distinct Immune Microenvironment in Hepatitis B Virus-Related Hepatocellular Carcinoma. Gut 68, 916-927. doi:10.1136/gutjnl-2018-316510

Lin, L., Chen, S., Wang, H., Gao, B., Kallakury, B., Bhuvaneshwar, K., et al. (2021). SPTBN1 Inhibits Inflammatory Responses and Hepatocarcinogenesis via the Stabilization of SOCS1 and Downregulation of P65 in Hepatocellular Carcinoma. Theranostics 11, 4232-4250. doi:10.7150/thno.49819

Lin, W., Chen, Y. L., Jiang, L., and Chen, J. K. (2011). Reduced Expression of Chemerin Is Associated with a Poor Prognosis and a Lowed Infiltration of Both Dendritic Cells and Natural Killer Cells in Human Hepatocellular Carcinoma. Clin. Lab. 57, 879-885. 
Lin, Y., Yang, X., Liu, W., Li, B., Yin, W., Shi, Y., et al. (2017). Chemerin Has a Protective Role in Hepatocellular Carcinoma by Inhibiting the Expression of IL6 and GM-CSF and MDSC Accumulation. Oncogene 36, 3599-3608. doi:10.1038/onc.2016.516

Liu, B., Ye, S., He, P., Zheng, N., Zhao, Y., Sun, R., et al. (2001). Study of the Cytotoxity against Human Hepatocellular Carcinoma Cells Induced by the MAGE-1 Gene Modified Dendritic Cells. Zhonghua Gan Zang Bing Za Zhi 9, 151-153.

Liu, C., Liu, L., Chen, X., Cheng, J., Zhang, H., Zhang, C., et al. (2018). LSD1 Stimulates Cancer-Associated Fibroblasts to Drive Notch3-dependent SelfRenewal of Liver Cancer Stem-like Cells. Cancer Res. 78, 938-949. doi:10.1158/0008-5472.can-17-1236

Liu, D., Li, G., Avella, D. M., Kimchi, E. T., Kaifi, J. T., Rubinstein, M. P., et al. (2017). Sunitinib Represses Regulatory T Cells to Overcome Immunotolerance in a Murine Model of Hepatocellular Cancer. Oncoimmunology 7, e1372079. doi:10.1080/2162402x.2017.1372079

Liu, G., Sun, J., Yang, Z.-F., Zhou, C., Zhou, P.-Y., Guan, R.-Y., et al. (2021). Cancer-associated Fibroblast-Derived CXCL11 Modulates Hepatocellular Carcinoma Cell Migration and Tumor Metastasis through the circUBAP2/ miR-4756/IFIT1/3 axis. Cell Death Dis 12, 260. doi:10.1038/s41419-02103545-7

Liu, J., Chen, S., Wang, W., Ning, B.-F., Chen, F., Shen, W., et al. (2016). Cancerassociated Fibroblasts Promote Hepatocellular Carcinoma Metastasis through Chemokine-Activated Hedgehog and TGF- $\beta$ Pathways. Cancer Lett. 379, 49-59. doi:10.1016/j.canlet.2016.05.022

Liu, M., Zhou, J., Liu, X., Feng, Y., Yang, W., Wu, F., et al. (2020). Targeting Monocyte-Intrinsic Enhancer Reprogramming Improves Immunotherapy Efficacy in Hepatocellular Carcinoma. Gut 69, 365-379. doi:10.1136/gutjnl2018-317257

Liu, R.-X., Wei, Y., Zeng, Q.-H., Chan, K.-W., Xiao, X., Zhao, X.-Y., et al. (2015). Chemokine (C-X-C Motif) Receptor 3-positive B Cells Link Interleukin-17 Inflammation to Protumorigenic Macrophage Polarization in Human Hepatocellular Carcinoma. Hepatology 62, 1779-1790. doi:10.1002/hep.28020

Liu, Y.-T., Tseng, T.-C., Soong, R.-S., Peng, C.-Y., Cheng, Y.-H., Huang, S.-F., et al. (2018). A Novel Spontaneous Hepatocellular Carcinoma Mouse Model for Studying T-Cell Exhaustion in the Tumor Microenvironment. J. Immunotherapy Cancer 6, 144. doi:10.1186/s40425-018-0462-3

Liu, Z., Chen, M., Zhao, R., Huang, Y., Liu, F., Li, B., et al. (2020). CAF-induced Placental Growth Factor Facilitates Neoangiogenesis in Hepatocellular Carcinoma. Acta Biochim. Biophys. Sin(shanghai). 52, 18-25. doi:10.1093/abbs/gmz134

Liu, Z., Wang, J., Liu, L., Yuan, H., Bu, Y., Feng, J., et al. (2020). Chronic Ethanol Consumption and HBV Induce Abnormal Lipid Metabolism through $\mathrm{HBx} /$ SWELL1/arachidonic Acid Signaling and Activate Tregs in HBV-Tg Mice. Theranostics 10, 9249-9267. doi:10.7150/thno.46005

Lo Re, O., Mazza, T., Giallongo, S., Sanna, P., Rappa, F., Vinh Luong, T., et al. (2020). Loss of Histone macroH2Al in Hepatocellular Carcinoma Cells Promotes Paracrine-Mediated Chemoresistance and CD4+CD25+FoxP3+ Regulatory $\mathrm{T}$ Cells Activation. Theranostics 10, 910-924. doi:10.7150/ thno. 35045

Long, J., Zhou, B., Li, H., Dai, Q., Zhang, B., Xing, S., et al. (2013). Improvement of HBsAg Gene-Modified Dendritic Cell-Based Vaccine Efficacy by Optimizing Immunization Method or the Application of $\beta$-glucosylceramide. Immunological Invest. 42, 137-155. doi:10.3109/08820139.2012.744418

Lv, B., Zhu, W., and Feng, C. (2020). Coptisine Blocks Secretion of Exosomal circCCT3 from Cancer-Associated Fibroblasts to Reprogram Glucose Metabolism in Hepatocellular Carcinoma. DNA Cell Biol 8, 1. doi:10.1089/ dna. 2020.6058

Ma, J., Zheng, B., Goswami, S., Meng, L., Zhang, D., Cao, C., et al. (2019). PD1Hi CD8+ T Cells Correlate with Exhausted Signature and Poor Clinical Outcome in Hepatocellular Carcinoma. J. Immunotherapy Cancer 7, 331. doi:10.1186/ s40425-019-0814-7

Ma, L., Luo, L., Qiao, H., Dong, X., Pan, S., Jiang, H., et al. (2007). Complete Eradication of Hepatocellular Carcinomas by Combined Vasostatin Gene Therapy and B7H3-Mediated Immunotherapy. J. Hepatol. 46, 98-106. doi:10.1016/j.jhep.2006.07.031

Mackey, M. F., Gunn, J. R., Ting, P. P., Kikutani, H., Dranoff, G., Noelle, R. J., et al. (1997). Protective Immunity Induced by Tumor Vaccines Requires Interaction between CD40 and its Ligand, CD154. Cancer Res. 57, 2569-2574.
Mackey, M. F., Barth, R. J., Jr., and Noelle, R. J. (1998). The Role of CD40/CD154 Interactions in the Priming, Differentiation, and Effector Function of Helper and Cytotoxic T Cells. J. Leukoc. Biol. 63, 418-428. doi:10.1002/jlb.63.4.418

Mano, Y., Yoshio, S., Shoji, H., Tomonari, S., Aoki, Y., Aoyanagi, N., et al. (2019). Bone Morphogenetic Protein 4 Provides Cancer-Supportive Phenotypes to Liver Fibroblasts in Patients with Hepatocellular Carcinoma. J. Gastroenterol. 54, 1007-1018. doi:10.1007/s00535-019-01579-5

Mantovani, S., Oliviero, B., Lombardi, A., Varchetta, S., Mele, D., Sangiovanni, A. et al. (2019). Deficient Natural Killer Cell NKp30-Mediated Function and Altered NCR3 Splice Variants in Hepatocellular Carcinoma. Hepatology 69, 1165-1179. doi:10.1002/hep.30235

Menne, S., Tumas, D. B., Liu, K. H., Thampi, L., AlDeghaither, D., Baldwin, B. H., et al. (2015). Sustained Efficacy and Seroconversion with the Toll-like Receptor 7 Agonist GS-9620 in the Woodchuck Model of Chronic Hepatitis B. J. Hepatol. 62, 1237-1245. doi:10.1016/j.jhep.2014.12.026

Mizukoshi, E., Yamashita, T., Arai, K., Terashima, T., Kitahara, M., Nakagawa, H., et al. (2016). Myeloid-derived Suppressor Cells Correlate with Patient Outcomes in Hepatic Arterial Infusion Chemotherapy for Hepatocellular Carcinoma. Cancer Immunol. Immunother. 65, 715-725. doi:10.1007/ s00262-016-1837-2

Morén, A., Bellomo, C., Tsubakihara, Y., Kardassis, D., Mikulits, W., Heldin, C.-H., et al. (2019). LXR $\alpha$ Limits TGF $\beta$-dependent Hepatocellular Carcinoma Associated Fibroblast Differentiation. Oncogenesis 8, 36. doi:10.1038/s41389019-0140-4

Mossanen, J. C., Kohlhepp, M., Wehr, A., Krenkel, O., Liepelt, A., Roeth, A. A., et al. (2019). CXCR6 Inhibits Hepatocarcinogenesis by Promoting Natural Killer Tand CD4+ T-cell-dependent Control of Senescence. Gastroenterology 156, 1877-1889. doi:10.1053/j.gastro.2019.01.247

Ning, J., Ye, Y., Bu, D., Zhao, G., Song, T., Liu, P., et al. (2021). Imbalance of TGFB1/bmp-7 Pathways Induced by M2-Polarized Macrophages Promotes Hepatocellular Carcinoma Aggressiveness. Mol. Ther. 29, 2067-2087. doi:10.1016/j.ymthe.2021.02.016

O'Beirne, J., Farzaneh, F., and Harrison, P. M. (2010). Generation of Functional CD8+ T Cells by Human Dendritic Cells Expressing Glypican-3 Epitopes. J. Exp. Clin. Cancer Res. 29, 48. doi:10.1186/1756-9966-29-48

Ormandy, L. A., Farber, A., Cantz, T., Petrykowska, S., Wedemeyer, H., Horning, M., et al. (2006). Direct Ex Vivo Analysis of Dendritic Cells in Patients with Hepatocellular Carcinoma. Wjg 12, 3275-3282. doi:10.3748/wjg.v12.i20.3275

Ouyang, F.-Z., Wu, R.-Q., Wei, Y., Liu, R.-X., Yang, D., Xiao, X., et al. (2016). Dendritic Cell-Elicited B-Cell Activation Fosters Immune Privilege via IL-10 Signals in Hepatocellular Carcinoma. Nat. Commun. 7, 13453. doi:10.1038/ ncomms 13453

Pang, P. H.-S., Chan, K.-T., Tse, L. Y.-W., Chan, R. C.-F., Cheung, Y.-K., Sin, F. W.Y., et al. (2007). Induction of Cytotoxic T Cell Response against HCA661 Positive Cancer Cells through Activation with Novel HLA-A*0201 Restricted Epitopes. Cancer Lett. 256, 178-185. doi:10.1016/j.canlet.2007.06.002

Papalexi, E., and Satija, R. (2018). Single-cell RNA Sequencing to Explore Immune Cell Heterogeneity. Nat. Rev. Immunol. 18, 35-45. doi:10.1038/nri.2017.76

Park, H., Jung, J. H., Jung, M. K., Shin, E.-C., Ro, S. W., Park, J. H., et al. (2020). Effects of Transarterial Chemoembolization on Regulatory $\mathrm{T}$ Cell and its Subpopulations in Patients with Hepatocellular Carcinoma. Hepatol. Int. 14, 249-258. doi:10.1007/s12072-020-10014-4

Pedroza-Gonzalez, A., Verhoef, C., Ijzermans, J. N. M., Peppelenbosch, M. P., Kwekkeboom, J., Verheij, J., et al. (2013). Activated Tumor-Infiltrating CD4+ Regulatory T Cells Restrain Antitumor Immunity in Patients with Primary or Metastatic Liver Cancer. Hepatology 57, 183-194. doi:10.1002/hep.26013

Peng, B. G., He, Q., Liang, L. I., Xie, B. H., Hua, Y. P., Chen, Z. B., et al. (2006). Induction of Cytotoxic T-Lymphocyte Responses Using Dendritic Cells Transfected with Hepatocellular Carcinoma mRNA. Br. J. Biomed. Sci. 63, 123-128. doi:10.1080/09674845.2006.11732731

Peng, H., Xue, R., Ju, Z., Qiu, J., Wang, J., Yan, W., et al. (2020). Cancer-associated Fibroblasts Enhance the Chemoresistance of CD73+ Hepatocellular Carcinoma Cancer Cells via HGF-Met-Erk1/2 Pathway. Ann. Transl Med. 8, 856. doi:10.21037/atm-20-1038

Pinato, D. J., Howlett, S., Ottaviani, D., Urus, H., Patel, A., Mineo, T., et al. (2019). Association of Prior Antibiotic Treatment with Survival and Response to Immune Checkpoint Inhibitor Therapy in Patients with Cancer. JAMA Oncol. 5, 1774-1778. doi:10.1001/jamaoncol.2019.2785 
Pistore, C., Giannoni, E., Colangelo, T., Rizzo, F., Magnani, E., Muccillo, L., et al. (2017). DNA Methylation Variations Are Required for Epithelial-ToMesenchymal Transition Induced by Cancer-Associated Fibroblasts in Prostate Cancer Cells. Oncogene 36, 5551-5566. doi:10.1038/onc.2017.159

Qin, W.-H., Yang, Z.-S., Li, M., Chen, Y., Zhao, X.-F., Qin, Y.-Y., et al. (2020). High Serum Levels of Cholesterol Increase Antitumor Functions of Nature Killer Cells and Reduce Growth of Liver Tumors in Mice. Gastroenterology 158, 1713-1727. doi:10.1053/j.gastro.2020.01.028

Qiu, S.-J., Lu, L., Qiao, C., Wang, L., Wang, Z., Xiao, X., et al. (2005). Induction of Tumor Immunity and Cytotoxic T Lymphocyte Responses Using Dendritic Cells Transduced by Adenoviral Vectors Encoding HBsAg: Comparison to Protein Immunization. J. Cancer Res. Clin. Oncol. 131, 429-438. doi:10.1007/ s00432-004-0616-1

Ren, Z., Yue, Y., Zhang, Y., Dong, J., Liu, Y., Yang, X., et al. (2021). Changes in the Peripheral Blood Treg Cell Proportion in Hepatocellular Carcinoma Patients after Transarterial Chemoembolization with Microparticles. Front. Immunol. 12, 624789. doi:10.3389/fimmu.2021.624789

Ritter, M., Ali, M. Y., Grimm, C. F., Weth, R., Mohr, L., Bocher, W. O., et al. (2004). Immunoregulation of Dendritic and T Cells by Alpha-Fetoprotein in Patients with Hepatocellular Carcinoma. J. Hepatol. 41, 999-1007. doi:10.1016/ j.jhep.2004.08.013

Rogler, G., Hausmann, M., Spöttl, T., Vogl, D., Aschenbrenner, E., Andus, T., et al. (1999). T-cell Co-stimulatory Molecules Are Upregulated on Intestinal Macrophages from Inflammatory Bowel Disease Mucosa. Eur. J. Gastroenterol. Hepatol. 11, 1105-1112. doi:10.1097/00042737-199910000-00006

Rohr-Udilova, N., Klinglmüller, F., Schulte-Hermann, R., Stift, J., Herac, M., Salzmann, M., et al. (2018). Deviations of the Immune Cell Landscape between Healthy Liver and Hepatocellular Carcinoma. Sci. Rep. 8, 6220. doi:10.1038/s41598-018-24437-5

Roxburgh, P., and Evans, T. R. J. (2008). Systemic Therapy of Hepatocellular Carcinoma: Are We Making Progress? Adv. Ther. 25, 1089-1104. doi:10.1007/ s12325-008-0113-z

Sakaguchi, S., Miyara, M., Costantino, C. M., and Hafler, D. A. (2010). FOXP3+ Regulatory T Cells in the Human Immune System. Nat. Rev. Immunol. 10, 490-500. doi:10.1038/nri2785

Samstein, R. M., Arvey, A., Josefowicz, S. Z., Peng, X., Reynolds, A., Sandstrom, R., et al. (2012). Foxp3 Exploits a Pre-existent Enhancer Landscape for Regulatory T Cell Lineage Specification. Cell 151, 153-166. doi:10.1016/j.cell.2012.06.053

Santos, P. M., Menk, A. V., Shi, J., Tsung, A., Delgoffe, G. M., and Butterfield, L. H. (2019). Tumor-Derived $\alpha$-Fetoprotein Suppresses Fatty Acid Metabolism and Oxidative Phosphorylation in Dendritic Cells. Cancer Immunol. Res. 7, 1001-1012. doi:10.1158/2326-6066.cir-18-0513

Sayem, M. A., Tomita, Y., Yuno, A., Hirayama, M., Irie, A., Tsukamoto, H., et al. (2016). Identification of Glypican-3-Derived Long Peptides Activating Both CD8+and CD4+T Cells; Prolonged Overall Survival in Cancer Patients with Th Cell Response. Oncoimmunology 5, e1062209. doi:10.1080/ 2162402x.2015.1062209

Schmitz, V., Barajas, M., Wang, L., Peng, D., Duarte, M., Prieto, J., et al. (2001). Adenovirus-mediated CD40 Ligand Gene Therapy in a Rat Model of Orthotopic Hepatocellular Carcinoma. Hepatology 34, 72-81. doi:10.1053/jhep.2001.25757

Schoenberger, S. P., Toes, R. E. M., van der Voort, E. I. H., Offringa, R., and Melief, C. J. M. (1998). T-cell Help for Cytotoxic T Lymphocytes Is Mediated by CD40Cd40l Interactions. Nature 393, 480-483. doi:10.1038/31002

Sconocchia, G., Eppenberger, S., Spagnoli, G. C., Tornillo, L., Droeser, R., Caratelli, S., et al. (2014). NK Cells and T Cells Cooperate during the Clinical Course of Colorectal Cancer. Oncoimmunology 3, e952197. doi:10.4161/ 21624011.2014.952197

Shao, Y., Lo, C. M., Ling, C. C., Liu, X. B., Ng, K. T.-P., Chu, A. C. Y., et al. (2014). Regulatory B Cells Accelerate Hepatocellular Carcinoma Progression via CD40/ CD154 Signaling Pathway. Cancer Lett. 355, 264-272. doi:10.1016/ j.canlet.2014.09.026

Shen, Y., Wei, Y., Wang, Z., Jing, Y., He, H., Yuan, J., et al. (2015). TGF- $\beta$ Regulates Hepatocellular Carcinoma Progression by Inducing Treg Cell Polarization. Cell Physiol Biochem 35, 1623-1632. doi:10.1159/000373976

Shi, F., Shi, M., Zeng, Z., Qi, R.-Z., Liu, Z.-W., Zhang, J.-Y., et al. (2011). PD-1 and PD-L1 Upregulation Promotes CD8+ T-Cell Apoptosis and Postoperative Recurrence in Hepatocellular Carcinoma Patients. Int. J. Cancer 128, 887-896. doi:10.1002/ijc.25397
Shimoda, M., Tomimaru, Y., Charpentier, K. P., Safran, H., Carlson, R. I., and Wands, J. (2012). Tumor Progression-Related Transmembrane Protein Aspartate- $\beta$-Hydroxylase Is a Target for Immunotherapy of Hepatocellular Carcinoma. J. Hepatol. 56, 1129-1135. doi:10.1016/j.jhep.2011.12.016

Sica, A., and Mantovani, A. (2012). Macrophage Plasticity and Polarization: In Vivo Veritas. J. Clin. Invest. 122, 787-795. doi:10.1172/jci59643

Soini, Y., Virkajarvi, N., Raunio, H., and Paakko, P. (1996). Expression of P-Glycoprotein in Hepatocellular Carcinoma: a Potential Marker of Prognosis. J. Clin. Pathol. 49, 470-473. doi:10.1136/jcp.49.6.470

Song, M., He, J., Pan, Q. Z., Yang, J., Zhao, J., Zhang, Y. J., et al. (2021). CancerAssociated Fibroblast-Mediated Cellular Crosstalk Supports Hepatocellular Carcinoma Progression. Hepatology 73, 1717-1735. doi: $10.1002 /$ hep. 31792

Spitzer, M. H., and Nolan, G. P. (2016). Mass Cytometry: Single Cells, Many Features. Cell 165, 780-791. doi:10.1016/j.cell.2016.04.019

Sprinzl, M. F., Reisinger, F., Puschnik, A., Ringelhan, M., Ackermann, K., Hartmann, D., et al. (2013). Sorafenib Perpetuates Cellular Anticancer Effector Functions by Modulating the Crosstalk between Macrophages and Natural Killer Cells. Hepatology 57, 2358-2368. doi:10.1002/ hep. 26328

Subleski, J. J., Scarzello, A. J., Alvord, W. G., Jiang, Q., Stauffer, J. K., Kronfli, A., et al. (2015). Serum-based Tracking of De Novo Initiated Liver Cancer Progression Reveals Early Immunoregulation and Response to Therapy. J. Hepatol. 63, 1181-1189. doi:10.1016/j.jhep.2015.06.021

Suk, K.-T., Mederacke, I., Gwak, G.-Y., Cho, S. W., Adeyemi, A., Friedman, R., et al. (2016). Opposite Roles of Cannabinoid Receptors 1 and 2 in Hepatocarcinogenesis. Gut 65, 1721-1732. doi:10.1136/gutjnl-2015-310212

Sukowati, C. H. C., Anfuso, B., Crocé, L. S., and Tiribelli, C. (2015). The Role of Multipotent Cancer Associated Fibroblasts in Hepatocarcinogenesis. BMC Cancer 15, 188. doi:10.1186/s12885-015-1196-y

Sun, H., Huang, Q., Huang, M., Wen, H., Lin, R., Zheng, M., et al. (2019). Human CD96 Correlates to Natural Killer Cell Exhaustion and Predicts the Prognosis of Human Hepatocellular Carcinoma. Hepatology 70, 168-183. doi:10.1002/ hep. 30347

Sun, L., Wang, Y., Wang, L., Yao, B., Chen, T., Li, Q., et al. (2019). Resolvin D1 Prevents Epithelial-Mesenchymal Transition and Reduces the Stemness Features of Hepatocellular Carcinoma by Inhibiting Paracrine of CancerAssociated Fibroblast-Derived COMP. J. Exp. Clin. Cancer Res. 38, 170. doi:10.1186/s13046-019-1163-6

Takata, Y., Nakamoto, Y., Nakada, A., Terashima, T., Arihara, F., Kitahara, M., et al. (2011). Frequency of CD45RO+ Subset in CD4+CD25high Regulatory T Cells Associated with Progression of Hepatocellular Carcinoma. Cancer Lett. 307, 165-173. doi:10.1016/j.canlet.2011.03.029

Tanaka, H., Yoshizawa, H., Yamaguchi, Y., Ito, K., Kagamu, H., Suzuki, E., et al. (1999). Successful Adoptive Immunotherapy of Murine Poorly Immunogenic Tumor with Specific Effector Cells Generated from Gene-Modified TumorPrimed Lymph Node Cells. J. Immunol. 162, 3574-3582.

Tao, H., Liu, M., Wang, Y., Luo, S., Xu, Y., Ye, B., et al. (2021). Icaritin Induces Anti-tumor Immune Responses in Hepatocellular Carcinoma by Inhibiting Splenic Myeloid-Derived Suppressor Cell Generation. Front. Immunol. 12, 609295. doi:10.3389/fimmu.2021.609295

Tao, Z., Ruan, H., Sun, L., Kuang, D., Song, Y., Wang, Q., et al. (2019). Targeting the YB-1/pd-L1 Axis to Enhance Chemotherapy and Antitumor Immunity. Cancer Immunol. Res. 7, 1135-1147. doi:10.1158/2326-6066.cir-18-0648

Teng, C. F., Wang, T., Wu, T. H., Lin, J. H., Shih, F. Y., Shyu, W. C., et al. (2020). Combination Therapy with Dendritic Cell Vaccine and Programmed Death Ligand 1 Immune Checkpoint Inhibitor for Hepatocellular Carcinoma in an Orthotopic Mouse Model. Ther. Adv. Med. Oncol. 12, 1758835920922034. doi:10.1177/1758835920922034

Tipton, K. N., Sullivan, N., Bruening, W., Inamdar, R., Launders, J., Uhl, S., et al. (2011). Stereotactic Body Radiation Therapy. Rockville(MD): Mayo Foundation for Medical Education and Research.

Tseng, H.-c., Xiong, W., Badeti, S., Yang, Y., Ma, M., Liu, T., et al. (2020). Efficacy of Anti-cd147 Chimeric Antigen Receptors Targeting Hepatocellular Carcinoma. Nat. Commun. 11, 4810. doi:10.1038/s41467-020-18444-2

Tsou, P., Katayama, H., Ostrin, E. J., and Hanash, S. M. (2016). The Emerging Role of B Cells in Tumor Immunity. Cancer Res. 76, 5597-5601. doi:10.1158/00085472.can-16-0431 
Veglia, F., Perego, M., and Gabrilovich, D. (2018). Myeloid-derived Suppressor Cells Coming of Age. Nat. Immunol. 19, 108-119. doi:10.1038/s41590-0170022-x

Vogt, A., Sievers, E., Lukacs-Kornek, V., Decker, G., Raskopf, E., Meumann, N., et al. (2014). Improving Immunotherapy of Hepatocellular Carcinoma (HCC) Using Dendritic Cells (DC) Engineered to Express IL-12 In Vivo. Liver Int. 34, 447-461. doi:10.1111/liv.12284

Voskoboinik, I., Smyth, M. J., and Trapani, J. A. (2006). Perforin-mediated TargetCell Death and Immune Homeostasis. Nat. Rev. Immunol. 6, 940-952. doi:10.1038/nri1983

Wang, C., Shang, C., Gai, X., Song, T., Han, S., Liu, Q., et al. (2021). Sulfatase 2Induced Cancer-Associated Fibroblasts Promote Hepatocellular Carcinoma Progression via Inhibition of Apoptosis and Induction of Epithelial-ToMesenchymal Transition. Front. Cell Dev. Biol. 9, 631931. doi:10.3389/ fcell.2021.631931

Wang, D., Li, X., Li, J., Lu, Y., Zhao, S., Tang, X., et al. (2019). APOBEC3B Interaction with PRC2 Modulates Microenvironment to Promote HCC Progression. Gut 68, 1846-1857. doi:10.1136/gutjnl-2018-317601

Wang, F., Jing, X., Li, G., Wang, T., Yang, B., Zhu, Z., et al. (2012). Foxp3+ Regulatory T Cells Are Associated with the Natural History of Chronic Hepatitis B and Poor Prognosis of Hepatocellular Carcinoma. Liver Int. 32, 644-655. doi:10.1111/j.1478-3231.2011.02675.x

Wang, H., Wang, X., Li, X., Fan, Y., Li, G., Guo, C., et al. (2014). CD68+HLA-DR+ M1-like Macrophages Promote Motility of HCC Cells via NF-Kb/FAK Pathway. Cancer Lett. 345, 91-99. doi:10.1016/j.canlet.2013.11.013

Wang, J., Sanmamed, M. F., Datar, I., Su, T. T., Ji, L., Sun, J., et al. (2019). Fibrinogen-like Protein 1 Is a Major Immune Inhibitory Ligand of LAG-3. Cell 176, 334-347. doi:10.1016/j.cell.2018.11.010

Wang, K., Nie, X., Rong, Z., Fan, T., Li, J., Wang, X., et al. (2017). B Lymphocytes Repress Hepatic Tumorigenesis but Not Development in Hras12V Transgenic Mice. Int. J. Cancer 141, 1201-1214. doi:10.1002/ijc.30823

Wang, N., Tan, H.-Y., Lu, Y., Chan, Y.-T., Wang, D., Guo, W., et al. (2021). PIWIL1 Governs the Crosstalk of Cancer Cell Metabolism and Immunosuppressive Microenvironment in Hepatocellular Carcinoma. Sig Transduct Target. Ther. 6, 86. doi:10.1038/s41392-021-00485-8

Wang, Y. H., Chuang, Y. H., Wu, C. F., Jan, M. C., Wu, W. J., Lin, C. L., et al. (2019). Smoking and Hepatitis B Virus-Related Hepatocellular Carcinoma Risk: The Mediating Roles of Viral Load and Alanine Aminotransferase. Hepatology 69, 1412-1425. doi:10.1002/hep.30339

Wang, Y., Liu, T., Tang, W., Deng, B., Chen, Y., Zhu, J., et al. (2016). Hepatocellular Carcinoma Cells Induce Regulatory T Cells and Lead to Poor Prognosis via Production of Transforming Growth Factor-B1. Cell Physiol Biochem 38, 306-318. doi:10.1159/000438631

Wei, Y., Lao, X.-M., Xiao, X., Wang, X.-Y., Wu, Z.-J., Zeng, Q.-H., et al. (2019). Plasma Cell Polarization to the Immunoglobulin $G$ Phenotype in Hepatocellular Carcinomas Involves Epigenetic Alterations and Promotes Hepatoma Progression in Mice. Gastroenterology 156, 1890-1904. e16. doi:10.1053/j.gastro.2019.01.250

Williams, M., Liu, X., Zhang, Y., Reske, J., Bahal, D., Gohl, T. G., et al. (2020). NCOA5 Deficiency Promotes a Unique Liver Protumorigenic Microenvironment through p21WAF1/CIP1 Overexpression, Which Is Reversed by Metformin. Oncogene 39, 3821-3836. doi:10.1038/s41388-0201256-x

Wolf, M. J., Adili, A., Piotrowitz, K., Abdullah, Z., Boege, Y., Stemmer, K., et al. (2014). Metabolic Activation of Intrahepatic CD8+ T Cells and NKT Cells Causes Nonalcoholic Steatohepatitis and Liver Cancer via Cross-Talk with Hepatocytes. Cancer Cell 26, 549-564. doi:10.1016/j.ccell.2014.09.003

Wong, Y. Q., Qiu, S. J., Tang, Z. Y., Ye, S. L., Liu, Y. K., Fan, J., et al. (2005). Changes in the Immune Function of Dendritic Cells (DC) Derived from HBV-Related Hepatocellular Carcinoma (HCC) Patient's Peripheral Blood Monocytes (PBMC) Pulsed with Tumor Antigen. Zhonghua Gan Zang Bing Za Zhi 13, 339-342.

Wu, C.-J., Tsai, Y.-T., Lee, I.-J., Wu, P.-Y., Lu, L.-S., Tsao, W.-S., et al. (2018). Combination of Radiation and Interleukin 12 Eradicates Large Orthotopic Hepatocellular Carcinoma through Immunomodulation of Tumor Microenvironment. Oncoimmunology 7, e1477459. doi:10.1080/ 2162402x.2018.1477459
Wu, J.-J., Yang, Y., Peng, W.-T., Sun, J.-C., Sun, W.-Y., and Wei, W. (2019). G Protein-Coupled Receptor Kinase 2 Regulating $\beta 2$-adrenergic Receptor Signaling in M2-Polarized Macrophages Contributes to Hepatocellular Carcinoma Progression. Ott 12, 5499-5513. doi:10.2147/ott.s209291

Wu, Q., Zhou, W., Yin, S., Zhou, Y., Chen, T., Qian, J., et al. (2019). Blocking Triggering Receptor Expressed on Myeloid Cells-1-Positive Tumor-Associated Macrophages Induced by Hypoxia Reverses Immunosuppression and AntiProgrammed Cell Death Ligand 1 Resistance in Liver Cancer. Hepatology 70, 198-214. doi:10.1002/hep.30593

Wu, Y., Kuang, D.-M., Pan, W.-D., Wan, Y.-L., Lao, X.-M., Wang, D., et al. (2013). Monocyte/macrophage-elicited Natural Killer Cell Dysfunction in Hepatocellular Carcinoma Is Mediated by CD48/2B4 Interactions. Hepatology 57, 1107-1116. doi:10.1002/hep.26192

Xiao, X., Lao, X.-M., Chen, M.-M., Liu, R.-X., Wei, Y., Ouyang, F.-Z., et al. (2016). PD-1hi Identifies a Novel Regulatory B-Cell Population in Human Hepatoma that Promotes Disease Progression. Cancer Discov. 6, 546-559. doi:10.1158/ 2159-8290.cd-15-1408

Xie, Q.-K., Zhao, Y.-J., Pan, T., Lyu, N., Mu, L.-W., Li, S.-L., et al. (2016). Programmed Death Ligand 1 as an Indicator of Pre-existing Adaptive Immune Responses in Human Hepatocellular Carcinoma. Oncoimmunology 5, e1181252. doi:10.1080/2162402x.2016.1181252

Xing, W., Wu, S., Yuan, X., Chen, Q., Shen, X., He, F., et al. (2009). The Anti-tumor Effect of Human Monocyte-Derived Dendritic Cells Loaded with HSV-TK/ GCV Induced Dying Cells. Cell Immunol. 254, 135-141. doi:10.1016/ j.cellimm.2008.08.004

Xiong, S., Wang, R., Chen, Q., Luo, J., Wang, J., Zhao, Z., et al. (2018). Cancerassociated Fibroblasts Promote Stem Cell-like Properties of Hepatocellular Carcinoma Cells through IL-6/STAT3/Notch Signaling. Am. J. Cancer Res. 8, 302-316.

Xu, Y., Fang, F., Jiao, H., Zheng, X., Huang, L., Yi, X., et al. (2019). Activated Hepatic Stellate Cells Regulate MDSC Migration through the SDF-1/CXCR4 axis in an Orthotopic Mouse Model of Hepatocellular Carcinoma. Cancer Immunol. Immunother. 68, 1959-1969. doi:10.1007/s00262-019-02414-9

Yamamoto, T., Nagano, H., Sakon, M., Wada, H., Eguchi, H., Kondo, M., et al. (2004). Partial Contribution of Tumor Necrosis Factor-Related ApoptosisInducing Ligand (TRAIL)/TRAIL Receptor Pathway to Antitumor Effects of Interferon-A/5-Fluorouracil against Hepatocellular Carcinoma. Clin. Cancer Res. 10, 7884-7895. doi:10.1158/1078-0432.ccr-04-0794

Yamanaka, T., Harimoto, N., Yokobori, T., Muranushi, R., Hoshino, K., Hagiwara, K., et al. (2021). Conophylline Inhibits HCC by Inhibiting Activated CancerAssociated Fibroblasts through Suppression of G Protein-Coupled Receptor 68. Mol. Cancer Ther. 20, 1019-1028. doi:10.1158/1535-7163

Yang, D., Li, T., Li, Y., Zhang, S., Li, W., Liang, H., et al. (2019). H2S Suppresses Indoleamine 2, 3-dioxygenase 1 and Exhibits Immunotherapeutic Efficacy in Murine Hepatocellular Carcinoma. J. Exp. Clin. Cancer Res. 38, 88. doi:10.1186/ s13046-019-1083-5

Yang, F., Wei, Y., Han, D., Li, Y., Shi, S., Jiao, D., et al. (2020). Interaction with CD68 and Regulation of GAS6 Expression by Endosialin in Fibroblasts Drives Recruitment and Polarization of Macrophages in Hepatocellular Carcinoma. Cancer Res. 80, 3892-3905. doi:10.1158/0008-5472.CAN-19-2691

Yang, J., Lu, Y., Lin, Y.-Y., Zheng, Z.-Y., Fang, J.-H., He, S., et al. (2016). Vascular Mimicry Formation Is Promoted by Paracrine TGF- $\beta$ and SDF1 of CancerAssociated Fibroblasts and Inhibited by miR-101 in Hepatocellular Carcinoma. Cancer Lett. 383, 18-27. doi:10.1016/j.canlet.2016.09.012

Yang, L., Shao, X., Jia, S., Zhang, Q., and Jin, Z. (2019). Interleukin-35 Dampens CD8+ $\mathrm{T}$ Cells Activity in Patients with Non-viral Hepatitis-Related Hepatocellular Carcinoma. Front. Immunol. 10, 1032. doi:10.3389/fimmu.2019.01032

Yang, M., Zhang, Z., Chen, J., Xu, M., Huang, J., Wang, M., et al. (2019). Soluble Fibrinogen-like Protein 2 Promotes the Growth of Hepatocellular Carcinoma via Attenuating Dendritic Cell-Mediated Cytotoxic T Cell Activity. J. Exp. Clin. Cancer Res. 38, 351. doi:10.1186/s13046-019-1326-5

Yang, T., Zhang, W., Wang, L., Xiao, C., Wang, L., Gong, Y., et al. (2018). Coculture of Dendritic Cells and Cytokine-Induced Killer Cells Effectively Suppresses Liver Cancer Stem Cell Growth by Inhibiting Pathways in the Immune System. BMC Cancer 18, 984. doi:10.1186/s12885-018-4871-y

Yang, X. H., Yamagiwa, S., Ichida, T., Matsuda, Y., Sugahara, S., Watanabe, H., et al. (2006). Increase of CD4+CD25+ Regulatory T-Cells in the Liver of Patients 
with Hepatocellular Carcinoma. J. Hepatol. 45, 254-262. doi:10.1016/ j.jhep.2006.01.036

Yang, Y. (2015). Cancer Immunotherapy: Harnessing the Immune System to Battle Cancer. J. Clin. Invest. 125, 3335-3337. doi:10.1172/jci83871

Yang, Y., Ye, Y.-C., Chen, Y., Zhao, J.-L., Gao, C.-C., Han, H., et al. (2018). Crosstalk between Hepatic Tumor Cells and Macrophages via Wnt/ $\beta$-Catenin Signaling Promotes M2-like Macrophage Polarization and Reinforces Tumor Malignant Behaviors. Cell Death Dis 9, 793. doi:10.1038/s41419-018-0818-0

Yao, R.-R., Li, J.-H., Zhang, R., Chen, R.-X., and Wang, Y.-H. (2018). M2-polarized Tumor-Associated Macrophages Facilitated Migration and EpithelialMesenchymal Transition of HCC Cells via the TLR4/STAT3 Signaling Pathway. World J. Surg. Onc 16, 9. doi:10.1186/s12957-018-1312-y

Ye, L., Zhang, Q., Cheng, Y., Chen, X., Wang, G., Shi, M., et al. (2018). Tumorderived Exosomal HMGB1 Fosters Hepatocellular Carcinoma Immune Evasion by Promoting TIM-1+ Regulatory B Cell Expansion. J. Immunotherapy Cancer 6, 145. doi:10.1186/s40425-018-0451-6

Yost, K. E., Satpathy, A. T., Wells, D. K., Qi, Y., Wang, C., Kageyama, R., et al. (2019). Clonal Replacement of Tumor-specific T Cells Following PD-1 Blockade. Nat. Med. 25, 1251-1259. doi:10.1038/s41591-019-0522-3

Yu, S. J., Ma, C., Heinrich, B., Brown, Z. J., Sandhu, M., Zhang, Q., et al. (2019). Targeting the Crosstalk between Cytokine-Induced Killer Cells and MyeloidDerived Suppressor Cells in Hepatocellular Carcinoma. J. Hepatol. 70, 449-457. doi:10.1016/j.jhep.2018.10.040

Yu, Z., Zhao, H., Feng, X., Li, H., Qiu, C., Yi, X., et al. (2019). Long Non-coding RNA FENDRR Acts as a miR-423-5p Sponge to Suppress the Treg-Mediated Immune Escape of Hepatocellular Carcinoma Cells. Mol. Ther. - Nucleic Acids 17, 516-529. doi:10.1016/j.omtn.2019.05.027

Yugawa, K., Yoshizumi, T., Mano, Y., Itoh, S., Harada, N., Ikegami, T., et al. (2021). Cancer-associated Fibroblasts Promote Hepatocellular Carcinoma Progression through Downregulation of Exosomal miR-150-3p. Eur. J. Surg. Oncol. 47, 384-393. doi:10.1016/j.ejso.2020.08.002

Zhang, D. Y., and Friedman, S. L. (2012). Fibrosis-dependent Mechanisms of Hepatocarcinogenesis. Hepatology 56, 769-775. doi:10.1002/hep.25670

Zhang, H.-G., Chen, H.-S., Peng, J.-R., Shang, X.-Y., Zhang, J., Xing, Q., et al. (2007). Specific CD8+ T Cell Responses to HLA-A2 Restricted MAGE-A3 P271-279 Peptide in Hepatocellular Carcinoma Patients without Vaccination. Cancer Immunol. Immunother. 56, 1945-1954. doi:10.1007/s00262-007-0338-8

Zhang, Q., Huang, H., Zheng, F., Liu, H., Qiu, F., Chen, Y., et al. (2020). Resveratrol Exerts Antitumor Effects by Downregulating CD8+CD122+ Tregs in Murine Hepatocellular Carcinoma. Oncoimmunology 9, 1829346. doi:10.1080/ 2162402x.2020.1829346

Zhang, X. D., Wang, Y., and Ye, L. H. (2014). Hepatitis B Virus X Protein Accelerates the Development of Hepatoma. Cancer Biol. Med. 11, 182-190. doi:10.7497/j.issn.2095-3941.2014.03.004

Zhang, Z., Li, X., Sun, W., Yue, S., Yang, J., Li, J., et al. (2017). Loss of Exosomal miR320a from Cancer-Associated Fibroblasts Contributes to HCC Proliferation and Metastasis. Cancer Lett. 397, 33-42. doi:10.1016/j.canlet.2017.03.004

Zhang, Z., Ma, L., Goswami, S., Ma, J., Zheng, B., Duan, M., et al. (2019). Landscape of Infiltrating B Cells and Their Clinical Significance in Human Hepatocellular Carcinoma. Oncoimmunology 8, e1571388. doi:10.1080/2162402x.2019.1571388

Zhao, J., Chu, F., Xu, H., Guo, M., Shan, S., Zheng, W., et al. (2020). C/EBPa/miR-7 Controls CD4+ T Cell Activation and Function and Orchestrates Experimental Autoimmune Hepatitis in Mice. Hepatology 1, 1. doi:10.1002/hep.31607

Zhao, Q., Huang, Z.-L., He, M., Gao, Z., and Kuang, D.-M. (2016). BTLA Identifies Dysfunctional PD-1-Expressing CD4+ T Cells in Human Hepatocellular Carcinoma. Oncoimmunology 5, e1254855. doi:10.1080/2162402x.2016.1254855

Zhao, T., Jia, H., Cheng, Q., Xiao, Y., Li, M., Ren, W., et al. (2017). Nifuroxazide Prompts Antitumor Immune Response of TCL-Loaded DC in Mice with Orthotopically-Implanted Hepatocarcinoma. Oncol. Rep. 37, 3405-3414. doi:10.3892/or.2017.5629

Zhao, X.-L., Lin, Y., Jiang, J., Tang, Z., Yang, S., Lu, L., et al. (2017). High-mobility Group Box 1 Released by Autophagic Cancer-Associated Fibroblasts Maintains the Stemness of Luminal Breast Cancer Cells. J. Pathol. 243, 376-389. doi:10.1002/path.4958

Zhao, Z., Bai, S., Wang, R., Xiong, S., Li, Y., Wang, X., et al. (2019). Cancerassociated Fibroblasts Endow Stem-like Qualities to Liver Cancer Cells by Modulating Autophagy. Cmar 11, 5737-5744. doi:10.2147/ cmar.s197634

Zheng, B. H., Ma, J. Q., Tian, L. Y., Dong, L. Q., Song, G. H., Pan, J. M., et al. (2020). The Distribution of Immune Cells within Combined Hepatocellular Carcinoma and Cholangiocarcinoma Predicts Clinical Outcome. Clin. Translational Med. 10, 45-56. doi:10.1002/ctm2.11

Zheng, B., Wang, D., Qiu, X., Luo, G., Wu, T., Yang, S., et al. (2020). Trajectory and Functional Analysis of PD-1 High CD4 + CD8 + T Cells in Hepatocellular Carcinoma by Single-Cell Cytometry and Transcriptome Sequencing. Adv. Sci. 7, 2000224. doi:10.1002/advs.202000224

Zheng, C., Zheng, L., Yoo, J.-K., Guo, H., Zhang, Y., Guo, X., et al. (2017). Landscape of Infiltrating T Cells in Liver Cancer Revealed by Single-Cell Sequencing. Cell 169, 1342-1356. doi:10.1016/j.cell.2017.05.035

Zhou, G., Sprengers, D., Boor, P. P. C., Doukas, M., Schutz, H., Mancham, S., et al. (2017). Antibodies against Immune Checkpoint Molecules Restore Functions of Tumor-Infiltrating T Cells in Hepatocellular Carcinomas. Gastroenterology 153, 1107-1119. doi:10.1053/j.gastro.2017.06.017

Zhou, J., Ding, T., Pan, W., Zhu, L.-y., Li, L., and Zheng, L. (2009). Increased Intratumoral Regulatory $\mathrm{T}$ Cells Are Related to Intratumoral Macrophages and Poor Prognosis in Hepatocellular Carcinoma Patients. Int. J. Cancer 125, 1640-1648. doi:10.1002/ijc.24556

Zhou, J., Liu, M., Sun, H., Feng, Y., Xu, L., Chan, A. W. H., et al. (2018). Hepatomaintrinsic CCRK Inhibition Diminishes Myeloid-Derived Suppressor Cell Immunosuppression and Enhances Immune-Checkpoint Blockade Efficacy. Gut 67, 931-944. doi:10.1136/gutjnl-2017-314032

Zhou, J., Nefedova, Y., Lei, A., and Gabrilovich, D. (2018). Neutrophils and PMNMDSC: Their Biological Role and Interaction with Stromal Cells. Semin. Immunol. 35, 19-28. doi:10.1016/j.smim.2017.12.004

Zhou, L., Fu, J.-L., Lu, Y.-Y., Fu, B.-Y., Wang, C.-P., An, L.-J., et al. (2010). Regulatory T Cells Are Associated with post-cryoablation Prognosis in Patients with Hepatitis B Virus-Related Hepatocellular Carcinoma. J. Gastroenterol. 45, 968-978. doi:10.1007/s00535-010-0243-3

Zhu, H.-f., Liu, Y.-p., Liu, D.-l., Ma, Y.-d., Hu, Z.-y., Wang, X.-y., et al. (2019). Role of TGF 33 -Smads-Sp1 axis in DcR3-Mediated Immune Escape of Hepatocellular Carcinoma. Oncogenesis 8, 43. doi:10.1038/ s41389-019-0152-0

Zigmond, E., Preston, S., Pappo, O., Lalazar, G., Margalit, M., Shalev, Z., et al. (2007). -Glucosylceramide: a Novel Method for Enhancement of Natural Killer T Lymphoycte Plasticity in Murine Models of Immune-Mediated Disorders. Gut 56, 82-89. doi:10.1136/gut.2006.095497

Conflict of Interest: The authors declare that the research was conducted in the absence of any commercial or financial relationships that could be construed as a potential conflict of interest.

Publisher's Note: All claims expressed in this article are solely those of the authors and do not necessarily represent those of their affiliated organizations, or those of the publisher, the editors and the reviewers. Any product that may be evaluated in this article, orclaim that may be made by its manufacturer, is not guaranteed or endorsed by the publisher.

Copyright (c) 2021 Hao, Sun, Zhang, Kong, Rong, Song, Tang and Wang. This is an open-access article distributed under the terms of the Creative Commons Attribution License (CC BY). The use, distribution or reproduction in other forums is permitted, provided the original author(s) and the copyright owner(s) are credited and that the original publication in this journal is cited, in accordance with accepted academic practice. No use, distribution or reproduction is permitted which does not comply with these terms. 